\title{
Clinical Characteristics and Current Therapies for Inherited Retinal Degenerations
}

\author{
José-Alain Sahel $\mathrm{I}^{1,2,3,4,5,6,7}$, Katia Marazova ${ }^{1,2,3}$, and Isabelle Audo ${ }^{1,2,3,4,7}$ \\ ${ }^{1}$ Institut de la Vision, Sorbonne Universités, UPMC Univ Paris 06, UMR_S 968, Paris, F-75012, France \\ ${ }^{2}$ INSERM, U968, Paris, F-75012, France \\ ${ }^{3}$ CNRS, UMR 7210, Paris, F-75012, France \\ ${ }^{4}$ Centre Hospitalier National d'Ophtalmologie des Quinze-Vingts, DHU ViewMaintain, INSERM-DHOS \\ CIC 1423, Paris, F-75012, France \\ ${ }^{5}$ Fondation Ophtalmologique Adolphe de Rothschild, Paris, F-75019, France \\ ${ }^{6}$ Académie des Sciences-Institut de France, Paris, F-75006, France \\ ${ }^{7}$ Institute of Ophthalmology-University College London, London EC1V 9EL, United Kingdom \\ Correspondence: j.sahel@gmail.com
}

\begin{abstract}
Inherited retinal degenerations (IRDs) encompass a large group of clinically and genetically heterogeneous diseases that affect approximately 1 in 3000 people ( $>2$ million people worldwide) (Bessant DA, Ali RR, Bhattacharya SS. 2001. Molecular genetics and prospects for therapy of the inherited retinal dystrophies. Curr Opin Genet Dev 11: 307-316.). IRDs may be inherited as Mendelian traits or through mitochondrial DNA, and may affect the entire retina (e.g., rod-cone dystrophy, also known as retinitis pigmentosa, cone dystrophy, conerod dystrophy, choroideremia, Usher syndrome, and Bardet-Bidel syndrome) or be restricted to the macula (e.g., Stargardt disease, Best disease, and Sorsby fundus dystrophy), ultimately leading to blindness. IRDs are a major cause of severe vision loss, with profound impact on patients and society. Although IRDs remain untreatable today, significant progress toward therapeutic strategies for IRDs has marked the past two decades. This progress has been based on better understanding of the pathophysiological pathways of these diseases and on technological advances.
\end{abstract}

\section{ROD-CONE DYSTROPHY}

Rod-cone dystrophies, also known as retiniRtis pigmentosa (RP), is a highly heterogeneous group of IRDs characterized by progressive bilateral degeneration of rod and cone photoreceptors. At present, there is no uniformly accepted classification of RP. The main crite- ria to classify RP include: (i) topography of the retinal involvement (central, pericentral, sector, or peripheral); (ii) age of onset; (iii) inheritance mode; and (iv) predominant type of photoreceptors involved. Many investigators divide RP into three main groups: nonsyndromic or "typical, classical, simple" (affecting the eye alone), syndromic (affecting other systems, such

Editors: Eric A. Pierce, Richard H. Masland, and Joan W. Miller

Additional Perspectives on Retinal Disorders: Genetic Approaches to Diagnosis and Treatment available at www.perspectivesinmedicine.org

Copyright (C) 2015 Cold Spring Harbor Laboratory Press; all rights reserved; doi: 10.1101/cshperspect.a017111 Cite this article as Cold Spring Harb Perspect Med 2015;5:a017111 
J.-A. Sahel et al.

as hearing), and systemic (affecting multiple tissues and organs). It is generally considered that $70 \%-80 \%$ of all RP cases fall in the category of nonsyndromic rod-cone dystrophy (Ayuso and Millan 2010).

In most forms of typical RP, degeneration of rod photoreceptors and loss of rod function precedes and exceeds cone degeneration. This is why the initial symptoms in RP, usually noted in childhood, are impaired dark adaptation and visual disturbances in dim light (nyctalopia). However, the age of onset may range widely, from early childhood to mid-30s to 50s or even later (Tsujikawa et al. 2008) and, in general, early-onset disease has worse prognosis. As $\mathrm{RP}$ advances, patients progressively lose their peripheral vision, while their central vision usually remains preserved until the late stages of the disease. This phenomenon is known as "tunnel vision." Light sensitivity (photophobia) may be present at a later stage of the disease. $\sim 35 \%$ of patients experience light flashes (photopsia) (Heckenlively et al. 1988), described as small, blinking lights that are often continuous but tend to decrease over the years as scotomas become denser. Loss of central vision usually occurs by age 60 , although most patients are legally blind by the age of $40 \mathrm{yr}$ because of severely constricted visual fields (Hartong et al. 2006).

\section{Clinical Characteristics of RP}

Clinical assessment of patients with RP (reviewed in Hartong et al. 2006) starts with complete past medical history and family history. Clinical tests that can reveal features of RP include psychophysical tests, slit lamp examination, fundus examination, electroretinogram (ERG), fundus autofluorescence, and spectral domain optical coherence tomography (OCT). Adaptive optics (described below) is a new tool for imaging cone photoreceptor matrix and is under evaluation for following-up cone disease in retinal dystrophies. Since the advent of fundus autofluorescence imaging, fluorescein angiography is no longer a diagnostic test for RP. Systemic evaluation and additional nonophthalmologic assessments (e.g., audiometric and vestibular tests, neurological examination, kidney function, and ultrasound) may be necessary to rule out syndromes and systemic disorders presenting with RP.

Psychophysical tests include best-corrected visual acuity measurement, which is usually normal in typical cases, even in advanced RP as long as a small area of central visual field is preserved. Kinetic and static perimetry typically show scotomas in the midperiphery that enlarge over years. Color vision (Farnsworth D15 panel or other tests) is usually preserved until advanced stages, when macular blue cone dysfunction (acquired tritanopia) may be apparent. Decline in contrast sensitivity (measured with a contrast chart) and fatigue are common complaints.

The early development of cataract is a common feature in RP, although the reasons for the capsular opacification remain poorly understood and may be because of vitreous changes and modification of blood-ocular barrier (reviewed in Jackson et al. 2001). Slit lamp examination reveals cataract, mainly of posterior subcapsular type, in up to $50 \%$ of adult RP patients and its incidence increases with age (Heckenlively 1982; Fishman et al. 1985). The mean age of surgery, as reported by Jackson et al. (2001) is $47.5 \mathrm{yr}$ versus $72.5 \mathrm{yr}$ for age-related cataract. In addition, RP patients tend to develop more posterior capsular opacification requiring YAG laser and zonular instability compared with age-related cataract (Dikopf et al. 2013). Keratoconus is rare and is usually encountered in early onset disease. Cells within the vitreous are common.

Results of fundus examination may vary with the stage of the disease and may initially be normal. The earliest changes are associated with fine, dust-like granularity of the retinal pigment epithelium (RPE), pigmentary mottling but with normal vasculature. In the middle stage of the disease, patchy loss of RPE and the beginning of retinal vessel attenuation are apparent. Advanced RP is characterized by arteriolar narrowing, waxy pallor of the optic nerve head, and migration of intraretinal pigment (termed bone spicule deposits) secondary to photoreceptor cell death. Cystoid macular edema is reported in $>40 \%$ of cases (Adackapara 
et al. 2008). Epimacular membrane is not uncommon. In addition, atrophic changes in the macula may also be observed early in some cases and represent another cause of earlier decrease in visual acuity in RP along with cystoid macular edema, epimacular membrane, and cataract.

Full-field Electroretinogram (ERG) is an objective method that records the electrical responses of the retina to light stimuli and is critical for the diagnosis of IRDs. The International Society for Clinical Electrophysiology of Vision (ISCEV) has elaborated recommendations for standardized minimal recording protocols (see http://www.iscev.org/), allowing for accurate diagnosis and inter-laboratory comparison. Full-field (Ganzfeld) ERG allows precise recording of both rod (after dark adaptation, scotopic conditions) and cone (after light adaptation, photopic conditions) photoreceptor function as well as response summation at the inner retinal level. ERG has not only diagnostic but also prognostic value, based on amplitude and implicit time preservation. In the early stages of $\mathrm{RP}$, scotopic responses are more affected than photopic responses, involving both the a-wave (hyperpolarization of photoreceptors-mostly rods - under dark adaptation) and the b-wave (generated at the inner retinal level on visual signal transmission from the photoreceptors). In case of sector RP (disease restricted to a retinal area, usually inferior), there is no implicit time shift. This is not the case in classical RP, which involves the entire retina. ERG abnormalities vary with the underlying genetic defect. $\mathrm{X}$-linked RP is associated with more severely affected ERG responses in comparison with autosomal recessive and dominant $\mathrm{RP}$, these two subgroups being characterized by a wider functional heterogeneity (Hartong et al. 2006). In later stages of the disease, the ERG responses become progressively lower to the point of being undetectable-even though visual acuity can be preserved, the electrical contribution of the macula to full-field ERG is negligible. In these cases, multifocal ERG or pattern ERG can be used to better assess macular function and objectively document disease progression toward the fovea (Hood et al. 1998; Robson et al. 2003). Special recording techniques have been developed to better document cone responses in case of submicrovolt photopic ERG responses (Andreasson et al. 1988; Birch and Sandberg 1996; Sieving et al. 1998).

Fundus autofluorescence is an efficient, noninvasive imaging method for topographic mapping of lipofuscin changes in the RPE and monitoring of retinal degeneration. In RP, decreased or absent fundus autofluorescence, usually observed in periphery, indicates loss of $\mathrm{RPE} /$ photoreceptor cells. A peculiar parafoveal ring of hyperautofluorescence was first reported by Robson et al. (2003) and may be present in $>60 \%$ of patients (Murakami et al. 2008). Its diameter correlates with preservation of macular (Fig. 1) function (Robson et al. 2003) and tends to constrict with disease progression (Robson et al. 2011). This ring, as functional correlate, may be used as a noninvasive outcome measurement in future clinical trials aimed at slowing disease progression.

Spectral domain OCT is now an established method for assessing retinal thickness and photoreceptor layer architecture. For example, the presence of the inner segment ellipsoid and interdigitation zone on OCT images highly correlates with normal visual function (Witkin et al. 2006; Mitamura et al. 2012). Spectral domain OCT is useful for detecting and monitoring macular edema as well as detecting epimacular membrane in RP patients (Koizumi et al. 2008; Hagiwara et al. 2011).

An adaptive optics fundus camera enables observation of cone photoreceptor mosaics in vivo (Fig. 2) (Gocho et al. 2013). The blurred areas of cone mosaics (heavily decreased density) in adaptive optics images correspond to the high-density fundus autofluorescence ring in fundus autofluorescence images and to the border of the external limiting membrane and the ellipsoid zone in OCT images (Tojo et al. 2013). Adaptive optics can therefore be useful in monitoring progression of RP and therapeutic intervention (Talcott et al. 2011).

\section{Epidemiology and Genetics of RP}

RP has an estimated worldwide prevalence of 1:3000-1:7000 persons (Bunker et al. 1984; 
J.-A. Sahel et al.
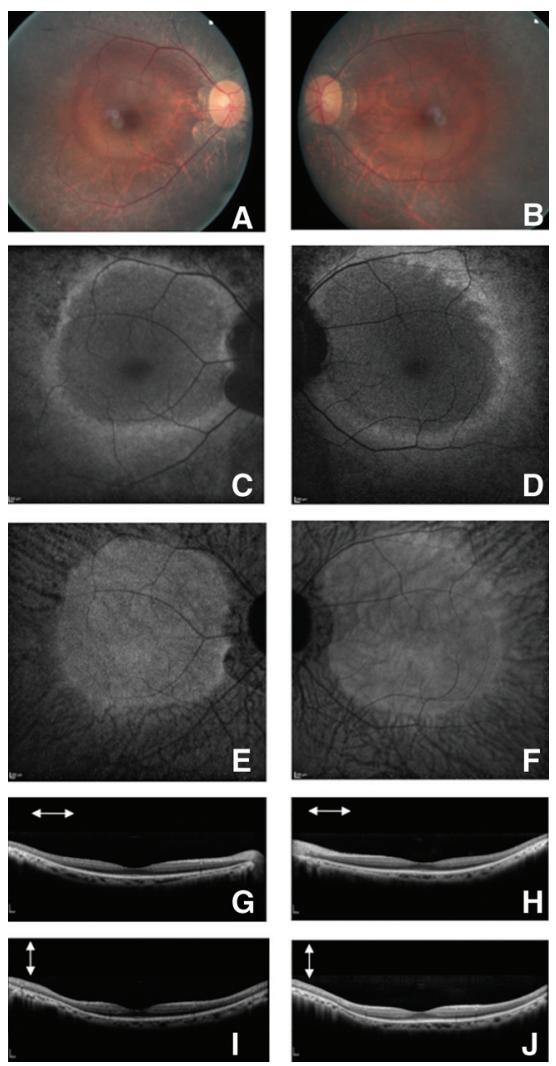

Figure 1. Fundus photographs, autofluorescence and spectral domain optical coherence tomography of a patient with rod-cone dystrophy (retinitis pigmentosa). Fundus photography ( $A$ right eye and $B$ left eye), Fundus autofluorescence blue ( $C$ right eye and $D$ left eye) and near infrared ( $E$ right eye and $F$ left eye) as well as Sd-OCT ( $G$ horizontal scan, $I$ vertical scan of the right eye, $H$ horizontal scan and $K$ vertical scan of the left eye) of a patient with rod-cone dystrophy (retinitis pigmentosa). On the color pictures note the waxy disc pallor of the optic disc, narrowed retinal vessels and preserved macular region with a high density ring of hyperautofluorescence around the macula associated with relatively preserved macular lamination on Sd-OCT.

Haim 2002). The substantial differences in epidemiological data reflect not only the variable criteria applied in different surveys, but also the substantial genetic diversity between populations in terms of prevalence of specific mutations and proportion of specific genetic types. On the basis of visual field criteria and ophthalmoscopic fundus appearance, the prevalence of
$\mathrm{RP}$ in adult population (aged $\geq 30 \mathrm{yr}$ ) of rural Central India was estimated at 1:750 (Nangia et al. 2012). High prevalence of 1:930 and 1:372 was reported in the urban and rural South Indian population aged above $40 \mathrm{yr}$ (Sen et al. 2008). The Beijing Eye Study reported RP in about one in 1000 elderly Chinese (aged $\geq 40$ yr) in North China (Jonas et al. 2009), whereas the Beijing Eye Public Health Care Project, a population-based study designed to screen all inhabitants aged of 55 to $85 \mathrm{yr}$ and living in the rural regions of the Beijing municipality, reported prevalence of RP of about 1:4000 (You et al. 2013). RP inheritance can be autosomal dominant, autosomal recessive, or X-linked, in addition to rare mitochondrial and digenic forms, and there is genetic heterogeneity within each group. Of the total number of nonsyndromic, nonsystemic cases, $\sim 19 \%$ are autosomal dominant, $65 \%$ are autosomal recessive or simplex cases, and $\sim 8 \%$ are $\mathrm{X}$ linked (Bunker et al. 1984). Population-based epidemiological and genetic study of X-linked $\mathrm{RP}$ (XLRP) in Denmark reported estimated prevalence of affected males of approximately 1:15,000 (Prokisch et al. 2007). The great success in identifying genes and mutations causing RP during the past two decades has revealed the tremendous genetic complexity of IRDs such as RP. According to the Retinal Information Network, RetNet, 232 genes causing IRDs have been mapped to a specific chromosomal site to date and 192 of these have been identified (see https://sph.uth.edu/retnet/sum-dis.htm, accessed May 30, 2013).

The first causative gene for RP, the rhodopsin gene $(R H O)$, was discovered in 1990 in autosomal dominant RP (Dryja et al. 1990). A majority of RP mutations affect rods selectively. However, the initial rod photoreceptor death is followed by secondary loss of cone photoreceptors that occurs regardless of the underlying mutation. The strikingly heterogeneous etiology of RP is complicated by the fact that mutations in many distinct genes can cause the same phenotype, mutations in the same gene may cause different diseases, and the same mutation in different individuals may be associated with wide range of phenotypic expressivity, even 


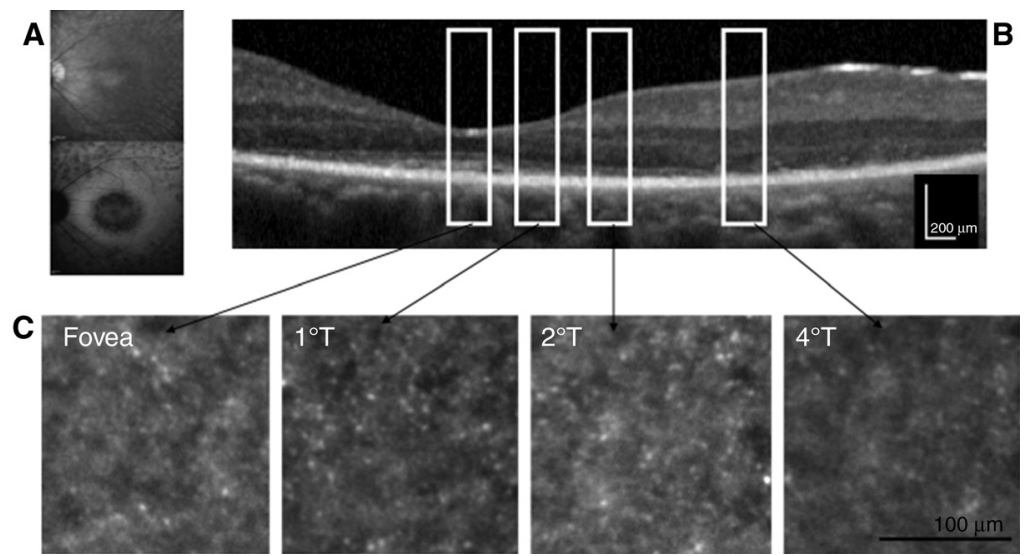

Figure 2. Adaptive optic images from the left eye of a patient with rod-cone dystrophy and perifoveal macular atrophy. (A) Infrared and blue autofluorescence from the left eye of the patient showing perifoveal loss of autofluorescence with relatively normal autofluorescence in the foveal region. (B) Sd-OCT horizontal scan of the left eye showing thinning of the outer retina with relatively normal foveal lamination with inner segment preservation up to $2^{\circ}$; white rectangles represent retinal location of the corresponding adaptive optics pictures. $(C)$ Adaptive optics imaging reveals that cones are still present around the fovea, but the cone mosaic is nearly absent at $4^{\circ}$. (Image courtesy of Kiyoko Gocho and Michel Paques.)

within the same family. For example, autosomal recessive RP can be caused by mutations in more than 44 genes identified so far; these include $R H O$ (Rosenfeld et al. 1992), the PDE- $\beta$ gene (encoding the $\beta$ subunit of rod cGMP phosphodiesterase) (McLaughlin et al. 1993) and the gene encoding the $\alpha$ subunit of the rod cGMP-gated channel (Dryja et al. 1995). At least 23 autosomal dominant RP genes have been identified to date and three of them, $R H O$, $R P 1$, and $P R P H 2$, account for approximately $25 \%-30 \%, 5 \%-10 \%$, and $5 \%-10 \%$ of all autosomal dominant RP cases, respectively. Similarly to $R H O$, mutations in $N R L$ can also cause either dominant or recessive disease. Mutations in the RPGR gene are associated with $\mathrm{X}$-linked RP (Roepman et al. 1996) and account for 70\% $90 \%$ of X-linked cases; another $10 \%-20 \%$ are caused by RP2 mutations. Mutations in some genes (e.g., PRPH2) can cause dominant RP, dominant macular degeneration or other distinct forms of retinopathy (Daiger et al. 2007). The functions of the genes involved in the pathogenesis of RP are highly variable. A majority of causative mutations are directly involved in the phototransduction cascade, for instance, rhodopsin $(R H O)$, the genes for the catalytic unit and subunits of PDE6 (PDE6A and PDE6B, respectively), the subunit of the rod cyclic nucleotide gated channel (CNGA1), and arrestin $(S A G)$. Some of these mutations cause not only RP but also other IRDs, including congenital stationary night blindness and cone dystrophies. Other mutated genes alter the function of proteins crucially involved in maintaining the visual cycle (e.g., RPE65, RLBP1, RGR, $A B C A 4)$ or photoreceptor structure (PRPH2, $R O M 1$ ), as well as transcription factors (e.g., NR2E3, NRL, CRX).

\section{Syndromic and Systemic Forms of RP}

Approximately $20 \%-30 \%$ of RP patients have associated syndromic nonocular disease or systemic conditions involving multiple organs and pleiotropic effects ( $>30$ different syndromes).

Usher syndrome is the most frequent form of syndromic RP, in which RP is associated with hearing impairment. It accounts for $\sim 18 \%$ of RP cases (Boughman et al. 1983). The disease is inherited in an autosomal recessive manner and is the most frequent cause of combined deafness and blindness in humans. It has a prevalence of about one in 20,000 in the Caucasian popula- 
J.-A. Sahel et al.

tion, but the estimations vary (e.g., 1:12,500 in Germany and 1:29,000 in persons of Scandinavian descent). Fifteen chromosomal loci and 12 genes have been identified so far and assigned to three major clinical types, depending on the severity and progression of the hearing loss, the coexistence with vestibular dysfunction and the age of onset of RP (Petit 2001) (RetNet database, see https://sph.uth.edu/retnet/). Symptoms vary from person to person and progress at different rates. Usher syndrome type $\mathrm{I}$ is the most severe form of the disease. It is characterized by congenital, bilateral, severe-to-profound, sensorineural hearing impairment associated with vestibular dysfunction. By the age of $\sim 10 \mathrm{yr}$, children experience progressive vision loss caused by RP. Balance disturbances result in retarded motor development. Usher syndrome type II is a less severe subtype, with moderateto-severe hearing impairment from birth, late onset of RP (after puberty), and normal vestibular function. In Usher syndrome type III, hearing loss begins in the first two decades of life and worsens over time, vision loss is progressive and variable in severity (starting around puberty), and vestibular dysfunction is variable.

Another major form of syndromic/systemic $\mathrm{RP}$ is Bardet-Biedl syndrome, in which RP is associated to varying degrees with polydactyly, obesity, type 2 diabetes, hypogonadism, cognitive impairment, and renal abnormalities that can be a major cause of morbidity and mortality in this syndrome (Forsythe and Beales 2012). The prevalence of Bardet-Biedl syndrome varies markedly between populations, from 1:160,000 in northern European populations to 1:13,500 in Kuwait (Forsythe and Beales 2012), and this form accounts for about $5 \%-6 \%$ of RP cases (Haim 2002). Currently, 16 genes are known to be associated with Bardet-Biedl syndrome, accounting for approximately $80 \%$ of clinically diagnosed cases (Forsythe and Beales 2012).

Recent evidence indicate that a number of multisystemic diseases, collectively termed ciliopathies, result from mutations in ciliary genes, including Joubert syndrome, nephronophthisis, Senior-Løken syndrome, orofaciodigital syndrome, Jeune syndrome, autosomal dominant and recessive polycystic kidney disease,
Leber congenital amaurosis, Bardet-Biedl syndrome, Meckel-Gruber syndrome, and Usher syndrome (Novarino et al. 2011). These clinically and genetically heterogeneous disorders share substantially overlapping clinical features, such as renal cysts, hepatic disease, retinal degeneration, polydactyly, cognitive impairment, sinus inversus, cerebellar hypoplasia, and obesity (Waters and Beales 2011).

Joubert syndrome (reviewed in Romani et al. 2013) is a complex ciliopathy, characterized by hypotonia progressing to ataxia, global developmental delay, ocular motor apraxia, breathing dysregulation, and, often renal defects and congenital liver fibrosis. The hallmark of the disease is the "molar tooth sign" visible on cerebral magnetic resonance imaging. Joubert syndrome is commonly associated with retinal defects that range in severity from Leber congenital amaurosis to slowly progressive retinopathies with partially preserved vision. Estimates of the incidence of Joubert syndrome range between $1: 80,000$ and 1:100,000 live births, but this is probably an underestimate. In the Askhenazi Jewish population, the predicted prevalence of Joubert syndrome is as high as one per 34,000 people. Today, 21 causative genes with autosomal or X-linked recessive inheritance have been identified, all of which encode for proteins of the primary cilium or its apparatus.

Senior-Løken syndrome is an autosomal recessive disease characterized by retinal dystrophy and a medullary cystic kidney disease, nephronophthisis. RP in Senior-Løken syndrome may present either as congenital retinal blindness caused by retinal dysplasia or as progressive retinal degeneration later in childhood (Waters and Beales 2011). So far, mutations in 13 genes coding for proteins in the connecting cilium of photoreceptor cells and in the primary cilium of kidney cells have been shown to cause Senior-Løken syndrome (reviewed in Ronquillo et al. 2012). Most of these mutations are also associated with pathologies in other organs, besides kidneys and retina.

Until now, $>80$ loci have been reported to be associated with ciliary disorders (van Reeuwijk et al. 2011). Intriguingly, mutations in CEP290 have been described in $~ 50 \%$ of Jou- 
bert syndrome subgroup of ciliopathies and up to $20 \%$ of cases of Leber congenital amaurosis, and found to be associated with a wide variety of distinct phenotypes, including Senior-Løken syndrome, nephronophthisis, Bardet-Biedl syndrome, and Meckel-Gruber syndrome (for review Coppieters et al. 2010; Waters and Beales 2011; Drivas et al. 2013). At present, despite the identification of more than 100 CEP290 mutations (Coppieters et al. 2010), no clear genotype-phenotype correlations could be established and the mechanisms underlying the highly variable phenotypes associated with ciliary dysfunction remain to be elucidated.

\section{CONE-ROD DYSTROPHIES}

Although most cases of RP are characterized by typical initial rod loss followed by the loss of cone photoreceptors, there are many inherited retinal diseases in which cone degeneration precedes the rod degeneration. These conditions are referred to as cone-rod degenerations/dystrophies (CORDs). Loss of visual acuity, color vision, and photophobia are characteristic early manifestations of the disease, with onset usually occurring in late childhood or early adult life, followed by night blindness and loss of peripheral visual fields (for a detailed review of clinical manifestations, see Michaelides et al. 2004). Macular pigment deposits and atrophy or a bull's-eye maculopathy are visible on fundus examination in the early stages. Peripheral RPE atrophy, retinal pigmentation, arteriolar attenuation, and optic disc pallor can be seen in the late stages of the disease process. Full-field ERG reveals a predominant alteration of photopic (absent or severely impaired cone function) over scotopic (rod) responses. The rate of disease progression varies widely between families. Visual acuity usually deteriorates severely over time, to the "counting fingers" level. Sometimes the loss of cones and rods is concomitant. CORDs can be inherited as autosomal recessive, autosomal dominant, X-linked, or mitochondrial traits. Most cases of progressive cone dystrophy and CORD are sporadic; autosomal dominant is the most common mode of inheritance in familial cases (Michaelides et al. 2004).
So far, mutations causing autosomal dominant CORDs have been identified in 10 genes, including two major genes being CRX (which also causes LCA7) and GUCY2D (which also causes LCA1), as well as AIPL1 (which also causes LCA4), GUCA1A, PITPNM3, PROM1, PRPH2, RIMS1, SEMA4A, and UNC119, and four loci: CORD4 (17q), RCD1 (6q25-q26), CORD16 (2q24.2-2q33.1), and 10q26 (Kamenarova et al. 2013). Most of the sporadic cases probably represent autosomal recessive inheritance, but some may represent new autosomal dominant mutations and, in severely affected males, $\mathrm{X}$-linked disease. Mutations in ABCA4 (also known to cause Stargardt disease 1) are responsible for $30 \%-60 \%$ of cases of autosomal recessive CORD; other genes associated with autosomal recessive CORDs include ADAM9, RPGRIP1, CDHR1, and HRG4. Mutations in $R P G R$, the gene encoding the protein that interacts with RPGRIP1, have been associated with X-linked CORD families. One additional chromosomal locus for X-linked CORD has been identified to date: CORDX3 (Xp11.4q13.1). CORDs are usually nonsyndromic, but they may also be associated with several syndromes, including Bardet-Biedl syndrome or spinocerebellar ataxia type 7 (Michaelides et al. 2004).

\section{LEBER CONGENITAL AMAUROSIS (LCA)}

LCA is a rare, infantile-onset retinal dystrophy with prevalence at birth of 1:30,000-1:80,000, accounting for $\sim 5 \%$ of all inherited retinopathies (reviewed in den Hollander et al. 2008). It is most commonly inherited as an autosomal recessive trait, but autosomal dominant forms have been linked to mutations in CRX and less commonly in IMPDH1 and OTX2. Two types of LCA exist with either rod-cone or cone-rod dysfunction in correlation with the underlying genetic defect. The constellation of severe and early visual loss, nystagmus, sluggish pupils and nondetectable ERG responses is pathognomic. Children with LCA may present with an oculodigital reflex and, in some cases, neurodevelopmental delay. Rare associated ocular features are strabismus, high hyperopia, high myopia, 
J.-A. Sahel et al.

cataracts, keratoconus/keratoglobus, macular pseudocoloboma, pigmentary retinopathy and maculopathy, disc edema, and retinal vascular attenuation (Koenekoop 2004). LCA is caused by mutations in any one of at least 18 genes (Falk et al. 2012; Koenekoop et al. 2012), (see https://sph.uth.edu/retnet/). At present, more than 400 mutations have been identified and associated with $\sim 70 \%$ of all LCA cases. LCA is currently considered to be the most severe retinal dystrophy without major systemic features.

\section{X-LINKED RETINOSCHISIS}

$\mathrm{X}$-linked retinoschisis is an inherited retinal disorder with estimated prevalence between 1:5,000 and 1:25,000 (George et al. 1995, 1996; The Retinoschisis Consortium 1998). X-linked retinoschisis accounts for almost all cases of congenital retinoschisis and is the leading cause of macular degeneration in young males. It is characterized by a splitting of the inner layers of the neurosensory retina, resulting in characteristic foveal schisis and vision loss. ERG has a characteristic "electronegative" appearance with relative loss of the positive, rod-driven b-wave and preservation of the negative a-wave (Sieving et al. 1999). X-linked retinoschisis is a clinically heterogenous disease (reviewed in George et al. 1996; Pimenides et al. 2005). It may be diagnosed either in infancy (with squinting, rarely nystagmus and severe vision loss) or at school age (with decreased visual acuity). The disease course may be variable and is usually mild until age $40 \mathrm{yr}$. The visual acuity thereafter declines progressively. Peripheral retinal abnormalities are seen in more than half of cases. Vitreous hemorrhage, retinal detachment, and neovascular glaucoma may occur. The disease is caused by mutations in the RS1 gene encoding retinoschisin, an important protein for cell adhesion (Sauer et al. 1997). More than 100 different mutations have been identified so far. Wide variations in clinical phenotype described between and within families are independent of the mutation type. Females who are homozygous for an RS1 mutation show similar symptoms and signs to affected males.

\section{STARGARDT DISEASE}

Stargardt disease, together with its phenotypic variant fundus flavimaculatus, is the most common macular degenerative disease in patients under $50 \mathrm{yr}$ of age. It is characterized by juvenile-onset, progressive, bilateral macular atrophy with subretinal deposition of lipofuscinlike material. Stargardt disease affects approximately one in 10,000 individuals (Blacharski 1988). However, the carrier frequency for a mutation in the causative gene may be as high as 1:20 (Yatsenko et al. 2001), thus explaining why pseudodominant cases are not uncommon. Typical Stargardt disease with macular atrophy is usually diagnosed before the age of 20 with impaired central and detailed vision and decreased visual acuity. Fundus flavimaculatus is usually diagnosed later. Later ages of onset have been associated with a more favorable visual prognosis. The disease manifests with decreased central vision that gradually worsens. Color vision may be variably affected with typical redgreen defect. Diagnosis is based on fundus examination, full-field and multifocal or pattern ERG, and fundus imaging (fundus autofluorescence and OCT). Fundus autofluorescence shows typically a loss of foveal autofluorescence, a patchy appearance of autofluorescence in the macular region with alternating hypo- and hyperautofluorescence dots and a peripapillary sparing of the autofluorescence (Fig. 3). Another historical hallmark feature of Stargardt disease is the presentation of a dark choroid during fluorescein angiography examination, which is not necessary for diagnosis since the advent of autofluorescence imaging. Full-field ERG has a prognostic value with three functional groups reported by the Moorfields team: group 1, characterized by restricted macular dysfunction, as documented with multifocal or pattern ERG, with normal scotopic and photopic full-field ERG; group 2, characterized by generalized cone dysfunction on the full-field ERG (abnormal photopic responses, but normal scotopic responses); and group 3, characterized by both cone and rod dysfunction on full-field ERG (both photopic and scotopic response abnormalities) (Lois et al. 2001). The three groups 
Clinical Characteristics and Current Therapies for IRDs
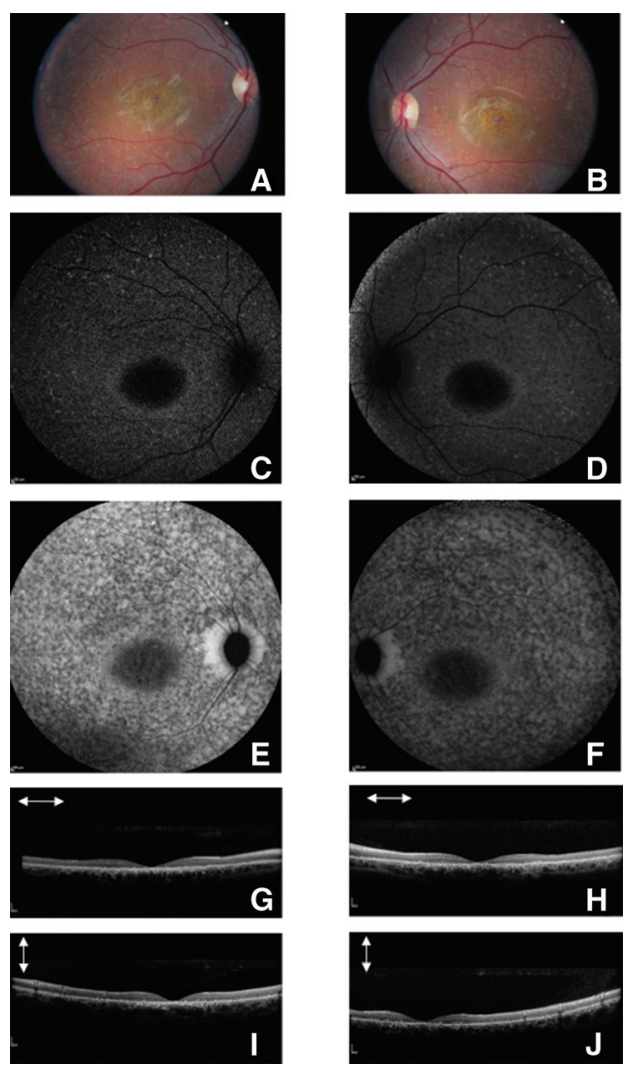

Figure 3. Fundus photographs, autofluorescence and spectral domain optical coherence tomography of a patient with Stargardt disease. Fundus photography ( $A$ right eye and $B$ left eye), fundus autofluorescence blue ( $C$ right eye and $D$ left eye), and near infrared ( $E$ right eye and $F$ left eye) as well as Sd-OCT ( $G$ horizontal scan, $I$ vertical scan of the right eye, $H$ horizontal scan and $K$ vertical scan of the left eye) of a patient with Stargardt disease. On the color pictures, note central macular atrophy with yellow dots in the mid-periphery. Fundus autofluorescence both on the blue and near infrared autofluorescence shows punctuate loss of autofluorescence in the mid-periphery with peripapillary sparing and loss of foveal autofluorescence in relation with macular atrophy; Sd-OCT reveal thinning of the outer retina in the foveal and parafoveal region.

illustrate the phenotypic variability associated with $A B C A 4$ mutations. Group 2 and group 3 are the most severe, with not only loss of central vision, but also progressive loss of peripheral visual fields and complete blindness. Such forms really represent a type of cone-rod dystrophy linked to $A B C A 4$ mutation.

Typically, Stargardt disease, reported for the first time by Karl Stargardt in 1909 (Stargardt 1909), is inherited as an autosomal recessive trait (Stargardt Disease 1, MIM \#248200) with mutations in the $A B C A 4$ gene on chromosome 1p13-p21 (Gerber et al. 1995; Allikmets et al. 1997). More than 600 disease-causing mutations have been identified so far. The ABCA4 (photoreceptor-specific ATP-binding cassette transporter 4) gene encodes for a retinal protein that is localized at the rims of the outer segments of both rod and cone photoreceptors (Sun and Nathans 1997). The retinal-specific ATP-binding cassette transporter protein has an essential role in the clearance of all-trans-retinal from the disk membranes after photoexcitation of rhodopsin (reviewed in Tsybovsky et al. 2010). Loss of protein function results in impaired transport of retinoids, accumulation of toxic substances (of which the best studied is A2E), and death of RPE cells and photoreceptors. As mentioned above, mutations in $A B C A 4$ are not only responsible for Stargardt disease, but are also a major cause of autosomal recessive CORD, and possibly also autosomal recessive RP (Sun and Nathans 1997; Cremers et al. 1998). The effects of the various mutations on ABCA4 protein function may be responsible for this phenotypic variability; nonsense or frameshift mutations with protein truncation being more commonly involved in CORD or RP than in typical Stargardt disease 1 (Sun and Nathans 1997). More recently, a few rare families have been reported with an autosomal dominant maculopathy with yellow flecks in the fundus resembling Stargardt disease (Stargardt disease, 3, MIM \#600110). This is caused by mutations in the ELOVL4 gene on chromosome 6q14.1 (Zhang et al. 2001).

\section{CHOROIDEREMIA}

Choroideremia is an X-linked retinal dystrophy that is characterized by progressive degeneration of the choriocapillaris, RPE, and photoreceptors, and progressive vision loss. Choroideremia typically affects males. Female carriers are usually asymptomatic, but retinal exams may show a 
J.-A. Sahel et al.

characteristic fundus appearance with irregular pigmentation on the fundus. Despite these widespread changes in the fundus, ERG is normal in female carriers ("dirty fundus, normal function"), although some cases of retinal degeneration have been reported (Potter et al. 2004). Night blindness occurring in early childhood is usually the first symptom of the disease. It is followed by progressive loss of the peripheral visual field (tunnel vision) and later decreased visual acuity. The disease is progressive, but, compared with X-linked RP, visual prognosis is more favorable and patients usually maintain good central vision until their 50s or 60s. Fullfield ERGs reveal rod-cone dysfunction: Scotopic responses with a reduction of the a-wave amplitude originating from rod photoreceptors are more severely affected than photopic responses. Fundus examination shows typical signs that distinguish choroideremia from RP: There is usually large scalloped chorioretinal atrophy with bare sclera in the periphery spreading toward the macula with little or no pigment migration. Unlike in RP, the optic nerve maintains its normal color until late in the course of the disease, and there is no narrowing of retinal blood vessels. Fundus autofluorescence reveals loss of autofluorescence in chorioretinal atrophic area with island of persistent autofluorescence, which, however, has a salt-and-pepper speckled appearance (Renner et al. 2006). OCT reveals thinning of both outer retinal structures and choriocapilaris that are sharply demarcated with evidence of retinal tabulation on the atrophic areas (Goldberg et al. 2013).

Choroideremia prevalence is estimated to be 1 in 50,000 to 100,000 people, accounting for $\sim 4 \%$ of all blindness (see http://ghr.nlm.nih .gov/condition/choroideremia). The disease is caused by mutations in the CHM gene (encoding Rab Escort Protein 1, REP-1) (Cremers et al. 1990) and more than 100 causative mutations have been described so far. REP-1 is involved in posttranslational lipid modification of Rabs (small Ras superfamily GTPases), which are key regulators of phagocytosis, secretion, and intracellular trafficking in a variety of tissues throughout the body (reviewed in Preising and Ayuso 2004).

\section{CONGENITAL STATIONARY NIGHT BLINDNESS}

Congenital stationary night blindness (CSNB) is a nonprogressive retinal degenerative disorder characterized by lifelong night blindness. The Schubert-Bornschein type is the most common type of CSNB, characterized by an electronegative response of the ERG to a bright white flash in the dark-adapted eye, with a normal a-wave and selective reduction of the b-wave amplitude resulting on a reduced b/a ratio. Electrophysiology is therefore critical for the diagnosis of CSNB. The disease is most commonly inherited as an $\mathrm{X}$-linked recessive trait, but can also have autosomal recessive and rarely autosomal dominant inheritance. Clinically, Schubert-Bornschien CSNB may present in two forms: complete and incomplete, according to whether there is a rod-specific ERG response to a dim light under dark adaptation (Miyake et al. 1986). Complete CSNB is characterized by severe night vision disturbances, nystagmus, high myopia and strabismus, reduced visual acuity, and severely reduced b-wave amplitude, with cone-specific ERG waveform abnormalities (Audo et al. 2008). Complete CSNB is caused by mutations in the gene NYX for X-linked forms, and in GRM6, TRPM1, GPR179, or LRIT3 for autosomal recessive inheritance. Incomplete CSNB has a more variable clinical manifestation, and light sensitivity is usually the main complaint, along with nystagmus, strabismus, and low vision. This form of CSNB is characterized by a reduced rod b-wave and substantially reduced cone responses. Incomplete CSNB has been associated with mutations in CACNA1F for the X-linked forms and in $C A B P 4$ and CACNA2D4 for the autosomal recessive forms (reviewed in Zeitz et al. 2013). To date, more than 300 mutations have been identified in the genes underlying CSNB. A less common form of CSNB has been reported by Riggs and is associated with severe rod photoreceptor dysfunction in association with mutations in genes involved in rod phototransduction cascade such as rhodopsin and the $\beta$ subunit of rod phosphodiesterases. This Riggs-type of CSNB is usually inherited as a dominant trait with normal daylight vision (reviewed by Dryja 2000). 


\section{ACHROMATOPSIA}

Achromatopsia, also called rod monochromacy or total congenital color blindness, is a congenital disorder with estimated prevalence of 1:30,000 (Michaelides et al. 2004). It is an autosomal recessive or X-linked disorder of the cone photoreceptors characterized by inability to distinguish colors, severely impaired visual acuity, photophobia, and nystagmus. The clinical manifestations occur early in infancy, and the disease course is usually nonprogressive. Spectral domain OCT may reveal foveal cone abnormalities (Genead et al. 2011). Five known autosomal recessive achromatopsia genes, CNGA3, CNGB3, GNAT2, PDE6C, and PDE6H (Kohl et al. 2012; Kohl and Hamel 2013), encode proteins in the cone phototransduction cascade, whereas the $\mathrm{X}$-linked form is associated with mutations in the gene encoding L- and M-opsin. Achromatopsia is characterized by phenotypic variability in terms of visual acuity, residual color vision, and some investigators have proposed the term "dysfunction syndrome" to encompass this phenotypic variability (Michaelides et al. 2004). Clinical diagnosis is established by standard ophthalmologic examination showing decreased visual acuity, usually around $20 / 200$, complete loss or only some residual color perception, normal fundus appearance or some foveal RPE changes, and, more importantly, by ERG recordings showing normal rod and nondetectable cone responses (Michaelides et al. 2004). The majority of human achromatopsia cases are caused by mutations in the CNGB3 gene (reported prevalence 50\%-90\% in patients of Northern European descent) (Komaromy et al. 2010).

\section{CURRENT THERAPIES FOR INHERITED RETINAL DISEASES}

\section{General Recommendations}

Currently, there is no effective treatment that can prevent or reverse vision loss in IRDs. General recommendations include supportive measures to maintain the activities of daily living and improve quality of life. Low vision rehabilitation (orientation and mobility training, educa- tional support, physical and occupational therapy) and optical and nonoptical corrective interventions (appropriate spectacles, high-intensity lamps, contrast-enhancing filters, nearand far magnification devices) should be proposed to all affected individuals. Limited exposure to sunlight and the use of green/blueblocking sunglasses are recommended. Avoiding smoking and retino-toxic medications such as Plaquenil $\AA^{\circledR}$ is highly advisable. Cystoid macular edema in patients with RP can be treated with oral or topical (less effective) carbonic anhydrase inhibitors (e.g., acetazolamide) (Fishman et al. 1989; Grover et al. 1997). As a general guideline, cataract surgery is indicated in individuals with lens opacities and should be performed as soon as it causes significant impairment of vision and before the disease evolves to a point at which it could limit postoperative recovery. In general, RP patients experience significant improvements in visual acuity after cataract surgery (reviewed in Bayyoud et al. 2013; Dikopf et al. 2013). However, patients should be informed that postoperative visual acuity cannot be accurately predicted before surgery because the part of cataract versus the part of macular dysfunction in the decrease of vision is sometime difficult to evaluate.

Vitamin A + / - lutein and omega-3 DHA can be used as nutritional supplements for patients with retinal degenerations, including $\mathrm{RP}$, in the absence of contraindications (Berson et al. 1993; Berson et al. 2004; Hoffman et al. 2004). Lutein and/or zeaxanthin (macular pigments from dietary sources) alone or in combination with vitamin A have shown some benefits in individuals with RP (e.g., increased macular pigment, decreased loss of visual field) (Aleman et al. 2001; Bahrami et al. 2006; Berson et al. 2010).

Although the general recommendations mentioned above may help, to some extent, to slow down the disease, there are, so far no curative treatment. Active research is being conducted to develop innovative treatments that address different aspects of the disease. These therapies aim to efficiently stop disease progression or restore some visual perception through genetargeting therapies or neuroprotection, or seek 
J.-A. Sahel et al.

to actively regenerate visual function through retinal prosthesis, optogenetics, cell based-therapies, or sensory substitution devices.

\section{Gene Therapy}

The past two decades have been marked by exceptional progress in understanding the biology and pathophysiology of the retina and identifying genes and mutations underlying IRDs. Despite this significant progress, the genetics of $\sim 50 \%$ of IRDs remain to be established (Hartong et al. 2006). With the first success of gene therapy for LCA, finding the genetic cause of IRD becomes increasingly important-not only for the correct diagnosis of retinal disease, but also for providing a key to genebased treatments. Gene therapy aims to replace, augment or "repair" the mutated and improperly functioning genes with normal genes that can restore protein function when expressed in retinal cells.

Most gene-mediated therapeutic strategies developed today use viral vectors that enable efficient gene delivery and stable transgene expression. The adenoviral vectors were among the first to be tested for retinal transduction (Bennett et al. 1994). These vectors have a relatively large cloning capacity, ranging from 8 to $\sim 40 \mathrm{~kb}$. Subretinal injections of adeniviral vector lead to efficient transduction of the RPE but limited transduction of the photoreceptors. In addition, these vectors are proinflammatory and immunogenic (Hoffman et al. 1997). Lentiviral vectors derived from human immunodeficiency virus 1 , almost completely devoid of viral coding sequences, have a cloning capacity in the range of $8-9 \mathrm{~kb}$ and are capable of transducing both dividing and nondividing cells (Naldini et al. 1996). In rodents, subretinal injection of lentiviral vector resulted in very effective targeting of the RPE, but targeting of retinal neurons appeared limited (Auricchio et al. 2001; Bemelmans et al. 2005). In addition, lentiviruses are RNAviruses, compared with adenoviruses and adeno-associated viruses (AAV), which are DNA viruses. Vectors in RNA viruses can potentially integrate at random positions in the genome, with potential subsequent carcino- genesis, whereas those from DNAviruses mainly remain episomal. This risk is limited in the eye, however, because subretinally injected viruses target postmitotic cells. AAV-derived vectors are currently the preferred vectors for ocular gene therapy because of several key properties. First, AAV vectors display low immunogenicity because their genome is completely devoid of viral coding sequences. Second, there are a variety of different $\mathrm{AAV}$ serotypes possessing distinct properties. For example, subretinal injection of serotype 4 specifically targets RPE cells, serotypes 7 and 8 are more specific for photoreceptors, and serotype 5 can target both layers with equivalent efficacy; intravitreal injection of AAV2 or 8 results in transduction of retinal ganglion cells (reviewed in Colella and Auricchio 2010). Finally, long-lasting transgene expression is achieved following AAV transduction-provided that the target cell survives and does not divide. In a majority of cases, this is an advantage, but it may also represent a disadvantage in cases that require cessation of treatment. Factors that determine the specificity or efficacy of retinal cell transduction include dose, administration route/site of delivery, disease state, animal model, and capsid (Vandenberghe and Auricchio 2012). Very efficient transduction of RPE (usually 100\% transduction in the area of detachment) and variable transduction of photoreceptors $(20 \%-80 \%$, depending on the serotype and titer used) were reported for all subretinally administered AAV serotypes (Vandenberghe and Auricchio 2012). To date, subretinal administration is the most efficient method for targeting photoreceptors and RPE cells, but it is technically more challenging than intravitreal injection and could be associated with postsurgical complications. Use of a newly developed AAV variant $(7 \mathrm{~m} 8)$ that mediates efficient panretinal delivery of the therapeutic gene from the vitreous has recently been reported in mice and nonhuman primates with X-linked retinoschisis and LCA (Dalkara et al. 2013). The $7 \mathrm{~m} 8$ vector enabled noninvasive, long-term histological and functional rescue of these disease phenotypes across the entire retina, offering clinically relevant implications for further gene therapy development. 
The therapeutic efficacy of the viral vectors has been shown in many experimental models of retinal disease, mainly those concerning monogenic recessive IRDs. In this case, a copy of the normal gene is introduced into an individual's target cells and tissues to prevent a disease, treat a disease, arrest disease progression, or slow down the degenerative process. Impressive rescue of retinal degeneration in animal models has been shown using adenovirus(Bennett et al. 1996), AAV- (Ali et al. 2000), or lentivirus-based vector technology (Tschernutter et al. 2005). Today, RPE65 gene-replacement is the most notable example of successful gene therapy for retinal degenerative disorders. Proof of concept for gene replacement therapy has been shown by the team of Jean Bennett (Acland et al. 2001) in the Swedish Briard dog, a model of human LCA. A single subretinal injection of AAV2.RPE65 restored visual function in this canine model of LCA in a safe, sustained, and long-term manner (Acland et al. 2005). On this basis, clinical trials of recombinant $\mathrm{AAV}$ (rAAV)-mediated gene therapy for patients with LCA have been implemented. Safety and efficacy of the gene transfer and stable rescue of visual function lasting for at least $3 \mathrm{yr}$ have been shown (Bainbridge et al. 2008; Hauswirth et al. 2008; Maguire et al. 2008; Jacobson et al. 2012; Testa et al. 2013). Readministration of AAV has been studied using bilateral subretinal injections in mouse (Barker et al. 2009), dog (Annear et al. 2011), and monkey (Amado et al. 2010) models of IRDs. Readministration of RPE65 gene-based treatment to the contralateral eye of adult patients with LCA was recently reported to evoke significantly greater responses in the second eye (Bennett et al. 2012), supporting the feasibility and benefits of repeated gene therapy in retinal degenerative diseases. Despite the improved vision after RPE65 gene augmentation therapy, however, photoreceptor degeneration was shown to progress both in the canine model and in humans (Cideciyan et al. 2013). This report directs attention to the need for further studies to assess the long-term safety, morphological outcomes, and functional benefits of gene therapy in LCA and other forms of retinal degeneration, and to evaluate combination therapies to improve vision and slow retinal degeneration in the long term. Nevertheless, the relatively good safety profile of the RPE65 gene replacement studies in humans has opened the path for other gene therapy studies.

Choroideremia, which is a recessive, monogenic retinal disorder without extraocular manifestations, could be considered an "ideal" target for gene augmentation therapy. As the CHM cDNA is $<4.7 \mathrm{~kb}$ in length, it is suitable for packaging in rAAV (Vasireddy et al. 2013). Despite these favorable factors, the main challenge in developing gene therapy for choroideremia at present remains the lack of an animal model that accurately reflects the human condition. Recently, it has been reported that subretinal injections of a lentiviral CHM/REP1 cDNA transgene resulted in efficient transduction of the RPE, longterm expression for at least 6 mo and a rescued prenylation defect in the CHM mouse (Tolmachova et al. 2012). An open-label, dose-escalation phase 1 clinical trial is being undertaken in Oxford University to assess the safety and tolerability of the AAV2.REP1 vector administered at two different doses to the retina in 12 choroideremia patients (see http://ClinicalTrials.gov .identifier: NCT01461213, PI: Rob McLaren). This gene therapy is expected to restore REP1 activity in the RPE of choroideremia patients. So far, six patients have been included with no major safety issues (MacLaren et al. 2014).

Applying a similar approach, an openlabel phase 1 study has been initiated by Dr. Alkuraya in Saudi Arabia, for gene replacement therapy of MERTK (rAAV2-VMD2-hMERTK) in patients with MERTK-associated retinal disease (see http://ClinicalTrials.gov. Identifier: NCT01482195). This study follows a proof-ofprinciple study in RCS rats (Conlon et al. 2013), a model of retinal degeneration. MERTK mutations are a rare cause of RP in humans and lead to retinal dystrophy in RCS rats.

Many preclinical studies using rAAVs are currently underway to prepare for future gene therapy trials. Targeted disorders include achromatopsia and X-linked retinoschisis. Canine CNGB3 mutations have been identified in Alaskan malamute and German shorthaired pointer breeds, providing a valuable system for studying 
J.-A. Sahel et al.

the disease mechanisms for achromatopsia and evaluating potential therapies (Sidjanin et al. 2002). A recent study in these naturally occurring canine models of a CNGB3 defect showed rescue of cone photoreceptor function after a single subretinal injection of rAAV5-mediated gene replacement therapy using different forms of the human red cone opsin promoter (Komaromy et al. 2010). The rescued cone function was documented by cone-specific ERG, and recovery of day vision was sustained for $>2 \mathrm{yr}$, suggesting that the correction is stable and probably permanent. Recent studies have also shown that AAV-mediated delivery (serotypes 2, 5, or 8 ) of the normal $R S 1$ gene can promote longterm rescue of retinal structure and function in a mouse model of X-linked retinoschisis (Zeng et al. 2004; Kjellstrom et al. 2007; Janssen et al. 2008; Park et al. 2009). Intravitreal administration of the $7 \mathrm{~m} 8$ vector $(7 \mathrm{~m} 8$-RS1) in the $R s 1 h$ knockout mouse led to high-level, panretinal RS1 expression in photoreceptors and throughout all other retinal layers, to levels comparable to wild-type for this secreted protein. This treatment led to substantial and stable improvements in rod and cone photoreceptor-mediated visual function and synaptic transmission (Dalkara et al. 2013). These studies provide substantial evidence that gene replacement therapy can be considered as a potential treatment for Xlinked retinoschisis.

The above-mentioned gene replacement studies targeted relatively small genes with relevant animal models for treatment validation through preclinical studies. Other diseases raise distinct challenges, including Stargardt disease and Usher syndrome, which have underlying genetic defects in large genes and lack animal models to obtain proof-of-principle validation of disease rescue. As mentioned above, the use of lentivirus vectors allows packaging of larger genes up to $9 \mathrm{~kb}$ and therefore offers a tool for delivery of genes that cannot be packaged in AAV. A better understanding of animal models that do not completely mimic human disease may allow identification of useful markers that are relevant in pathogenicity. Examples of such models include the $\mathrm{Abca}^{-/-}$mouse, which does not strictly develop the central photore- ceptor degeneration observed in Stargardt disease, but does show progressive accumulation of A2E, a major component of the disease process in humans (Cideciyan et al. 2004). Similarly, the shaker mouse, which has mutations in Myo7A (also mutated in Usher syndrome type IB), shows abnormal rhodopsin trafficking within rod outer segments and abnormal melanosomes in RPE cells (Liu et al. 1998, 1999). These markers have been very useful for validating gene replacement therapy in the respective models. High transduction efficiency of both rod and cone photoreceptors was observed after subretinal injection of equine infectious anemia virus (EIAV)-derived lentiviral vectors expressing human $A B C A 4$ gene in a mouse model of Stargardt disease, and correction of the disease phenotype was shown (Kong et al. 2008). This opened the way for clinical evaluation of lentiviral gene therapy as potentially efficient tool for treating retinal diseases. Indeed, three clinical trials are currently underway to evaluate the safety of StarGen ${ }^{\mathrm{TM}}$ (NCT01367444) in patients with Stargardt macular degeneration, UshStat ${ }^{\circledR}$ (NCT01505062) in patients with Usher Syndrome Type IB and RetinoStat ${ }^{\circledR}$ (NCT01301443) in patients with age-related macular degeneration, with all three vectors designed and developed by Oxford BioMedica using the company's proprietary LentiVector ${ }^{\circledR}$ gene delivery technology.

The large number of genes involved in the pathogenesis of IRDs is a major challenge for gene augmentation therapy today. Gene therapy may also not be suitable for autosomal dominant diseases with a dominant negative effect as the pathogenic mechanism. In such cases, suppression of the mutated copy may be more relevant (Farrar et al. 2010). Other important factors that should be taken into account when considering gene therapy include availability of relevant animal models with suitable disease markers, prevalence of the disorder, knowledge of the disorder's natural history to determine a suitable window for treatment, function of the transgene product, and risks associated with overexpression of the transgene. Therapeutic strategies that are independent of the disease-causing mutation thus carry a great potential in IRDs. 


\section{Neuroprotection}

A significant body of evidence has shown that neurotrophic factors such as brain-derived neurotrophic factor (BDNF), pigment epitheliumderived neurotrophic factor (PEDF), basic fibroblast growth factor (bFGF or FGF-2), and ciliary neurotrophic factor $(\mathrm{CNTF})$ slow retinal degeneration in a number of animal models. A phase 1 trial performed in ten patients with advanced RP for a period of 6 mo indicated that CNTF delivered by intraocular encapsulated cell technology (NT-501 implant, Neurotech USA) is safe for the human retina even with severely compromised photoreceptors (Sieving et al. 2006). A recent study spanning four clinical trials confirmed consistent safety of intraocular delivery of CNTF by intraocular encapsulated cell technology (NT-501 implants) over a 2-yr period in patients with RP and geographic atrophy (Kauper et al. 2012). However, these studies have so far failed to show functional rescue as measured by best-corrected visual acuity and visual field sensitivity at $12 \mathrm{mo}$ (Birch et al. 2013). A phase 1-2 clinical trial with an NT501 intraocular implant releasing CNTF to the retina of patients affected with CNGB3 achromatopsia is currently underway (see http:// ClinicalTrials.gov. Identifier: NCT01648452).

As previously emphasized, the initial loss of rods (owing to mutations in genes solely expressed in rods) is followed by degeneration of the cones, with loss of central vision and blindness. This is mechanistically puzzling, because the genetic lesion is present only in the rods. Preventing this secondary degeneration of cones may allow for treatment of a wide range of IRDs, as such therapy would be independent of the disease-causing mutation. Rod-derived cone viability factor (RdCVF) has been shown to induce cone survival and functional rescue in animal models of recessive and dominant RP (Leveillard et al. 2004; Yang et al. 2009) in a manner independent from either the mechanisms or extent of rod degeneration. RdCVF is now considered not only as an autocrine- and paracrine-acting neuroprotective agent but also as a physiological signal involved in the maintenance of photoreceptors, of importance dur- ing both aging and exposure to oxidative stress. It would be particularly well-suited for preventing the secondary degeneration of cones and for treating RP at a stage in which night blindness is associated with moderate central visual impairment (Leveillard and Sahel 2010).

\section{Alternative Pharmacological Approaches}

A variety of pharmacological strategies have shown some potential efficacy in treating retinal degeneration; these include retinoid replacement, valproic acid therapy, and treatment with calcium channel blockers. Mutations in LRAT and RPE65 cause disruption in 11-cis-retinal regeneration and account for $\sim 5 \%$ of all cases of LCA and RP (Thompson et al. 2001; Bereta et al. 2008). Pharmacological retinoid replacement therapy for 11-cis-retinal deficiency thus carries the potential for treatment of human disease. Indeed, administration of 9-cis-retinoid has been shown to bypass defects in the visual cycle, restore visual function and slow the progression of retinal degeneration in $\mathrm{Lrat}^{-/-}$ and Rpe65 $5^{-/-}$mice (Van Hooser et al. 2000; Maeda et al. 2009). Similarly, long-term treatment with the 9-cis-retinal analog QLT091001 was well-tolerated and able to maintain retinal thickness and morphology in $\mathrm{Lrat}^{-/-}$, Rpe $65^{-/-}$mice and Gnat $1^{-/-}$mice (Maeda et al. 2013). Based on these encouraging preclinical results, a safety proof-of-concept study to evaluate the effects of oral QLT091001 in RP subjects with an autosomal dominant mutation in RPE65 is currently underway (see http:// ClinicalTrials.gov. Identifier: NCT01543906). The antiepileptic drug valproic acid has some properties (neuroprotective and anti-inflammatory effects) and was also shown to act as a chaperone molecule for proper folding of rhodopsin mutants allowing to hypothesize potential therapeutic value in retinal degenerative diseases. A preliminary study with valproic acid had suggested therapeutic benefit in some patients with RP (Clemson et al. 2011). However, the long-term follow-up of $31 \mathrm{RP}$ patients revealed possible declines in visual acuity and field, suggesting caution in the use of this drug to treat pigmentary retinal dystrophies 
J.-A. Sahel et al.

(Bhalla et al. 2013). Efficacy and safety of oral valproic acid for RP is under clinical investigation (http://ClinicalTrials.gov. Identifier: NCT01399515). Some studies in animal models have shown that calcium channel blockers (e.g., diltiazem, nicardipine, nilvadipine, or nifedipine) inhibit photoreceptor degeneration (Frasson et al. 1999; Takano et al. 2004), and a 30-mo clinical trial recently reported that nilvadipine at $4 \mathrm{mg} / \mathrm{d}$ significantly retarded progression of central visual field defects in RP (Nakazawa et al. 2011).

\section{Retinal Prosthetics}

In IRDs, parts of the inner retina survive even after complete degeneration of the retinal photosensitive layer and remain responsive to electrical simulation even in late stages of the disease (Humayun et al. 1996). Visual neuroprosthetics use electrical stimulation to activate the remaining inner retinal network, allowing these cells to take over the function of the lost photoreceptors. Different groups worldwide are currently working on retinal implant devices. The longest and largest follow-up data at present were reported for the epiretinal implant Argus II, made by the U.S. company Second Sight Medical Products (Humayun et al. 2003). This device is positioned on the surface of the retina (between the surface of the vitreous and the retina). It communicates directly with the ganglion and bipolar cells, receiving light signals from an external camera system. Long-term safety results showed that $70 \%$ of patients with profound visual loss implanted with Argus II did not have any serious adverse events; most of them performed better on visual tasks, including object localization, motion- and oriented grating discrimination, identification of letters and words, and even reading short sentences (Humayun et al. 2012; da Cruz et al. 2013). Argus II can also simulate visual Braille as a sensory substitute for reading (Lauritzen et al. 2012). Argus II received the first-ever commercial use approval (Europe, 2011; the United States, 2013) for a retinal prosthesis device to treat adult patients with retinal degenerative diseases such as advanced RP.
Subretinal implants are positioned between the retina and the choroid to replace degenerated photoreceptors and receive light directly from the environment (Zrenner 2002). Because of the proximity to the surviving neurons in the visual pathway, this approach may offer better inherent mechanical stability and may possibly require less current for effective stimulation, but it remains challenging from a surgical point of view. Clinical trial data (NCT0102480) obtained with the subretinal device made by Retina Implant AG (the wirelessly powered subretinal implant alpha-IMS) in profoundly blind patients with RP showed stable visual percepts, restoration of useful vision in daily life, and even identification of objects and letters (Zrenner et al. 2011; Stingl et al. 2013). The subretinal implant technology of Retina Implant AG received CE marking in July 2013. In a novel prosthetic device, the photovoltaic subretinal prosthesis, video goggles deliver both power and visual information directly to each pixel through pulsed near-infrared illumination (Mathieson et al. 2012). The implant is thin and wireless, the surgical procedure appears simple, all pixels in it function independently, and the natural link between image perception and eye movement is preserved. Both epi- and subretinal implants require an intact optic nerve pathway to function. Despite the great technical progress, the quality of the images achieved with retinal prosthetic devices remains a challenge. New electrode designs and new materials aiming at improving visual resolution and safety profiles are currently under investigation.

\section{Optogenetics}

Optogenetics combines genetic strategies that target light-sensitive proteins within the cells and optical stimulation to activate these selectively targeted proteins. To restore useful vision in blind patients, optogenetics takes advantages of two facts: (i) Even after the occurrence of blindness caused by IRD, many cone photoreceptors survive and maintain their cell body for extended periods (Li et al. 1995, Lin et al. 2009); and (ii) the remarkable proteins channelrhodopsin-2 (ChR2) (Nagel et al. 2002; Boyden 
et al. 2005) and halorhodopsin (NpHR) (Zhang et al. 2007) function as light-gated ion channels. The key goal of optogenetic vision restoration is to convert strategically important retinal cell types into "artificial photoreceptors." Indeed, ChR2 has been targeted to ON bipolar cells of rd1 mice, after which cells with morphological features of $\mathrm{ON}$ ganglion cells responded to increases in light intensity. Light-evoked activity was measured in the cortex, and visually evoked behavior was documented (Lagali et al. 2008). Recent studies have shown that NpHR introduced to surviving cone cell bodies in two mouse models of $\mathrm{RP}$ reactivated retinal $\mathrm{ON}$ and OFF pathways, as well as the retinal circuitry, and enabled RP mice to perform visually guided behaviors (Busskamp et al. 2010). Moreover, NpHR targeted to human postmortem photoreceptors with no measurable intrinsic rodor cone-mediated photosensitivity restored light responses in photoreceptor cells, clearly showing that reactivation of the surviving retinal structures and phototransduction cascade required for vision is possible (Busskamp et al. 2010). These preclinical data hold promise that legally blind patients or severely visually impaired patients with no visual field but with a preserved layer of cone bodies (visible on OCT) could be eligible for optogenetic functional restoration of cones. Key advantages of optogenetics as a therapeutic approach for IRDs include: (i) It may provide artificially stimulated retinal activity that resembles the normal activity of retinal circuits, because these retinal cells are already connected to other retinal circuit elements in a biologically relevant way; and (ii) it is gene/mutation-independent. Different strategies for optogenetic vision restoration, including their advantages and possible combination with other methods to slow retinal degeneration and/or restore vision were recently reviewed in (Busskamp et al. 2011; Sahel and Roska 2013).

\section{Cellular Therapy}

Transplantation of retinal cells is another potential strategy to restore vision in patients with IRDs. Development of synaptic connections and functionality is of major importance, although efficacy and safety in implanting fetal retina with accompanying RPE in AMD and $\mathrm{RP}$ patients has already been reported (Radtke et al. 2008). Transplantation of photoreceptor precursor cells is an alternative approach. Indeed, initial data showed that transplanted progenitor or precursor cells isolated at the correct ontogenetic stage from the developing retina can integrate into the host retina and differentiate into rod photoreceptors (MacLaren et al. 2006). Recent findings confirmed the survival and differentiation of some photoreceptors derived from three-dimensional embryonic stem cell (ESC) cultures: ESC-derived photoreceptor cell precursors showed capability to integrate and mature, and to form outer segments and some synaptic connections after transplantation into the degenerate adult mouse retina, thus supporting the utility of ESC-derived cells for photoreceptor replacement therapy (whether similar integration can be achieved using human cells remains to be established as well as the functional improvement provided) (GonzalezCordero et al. 2013). The main advantage of cell therapies as a source for regenerative therapy is that they are gene-independent and thus can be applicable to broader range of retinal diseases. Pluripotent stem cells like human embryonic stem cells (hESCs) or human induced pluripotent stem cells (hiPSCs) can be expanded indefinitely in culture and could be used as an unlimited source of retinal cells for treatment of IRDs (Zhao et al. 2002; Osakada et al. 2008; Hirami et al. 2009; Lamba et al. 2009; Lamba et al. 2010). The first-ever safety and tolerability prospective clinical trial to evaluate subretinal injection of hESC-derived RPE cells in patients with dry age-related macular degeneration and Stargardt macular dystrophy (see http:// ClinicalTrials.gov. Identifier: NCT01345006) is currently underway, and very early results suggest no major safety concern (no signs of hyperproliferation, tumorigenicity, ectopic tissue formation, or apparent rejection after $4 \mathrm{mo}$ ) (Schwartz et al.2012). As hiPSCs can be obtained directly from the patient, they have the advantage of being autologous and therefore less-immunogenic than hESCs (although hiPSCs vary 
J.-A. Sahel et al.

in pluripotency and may differentiate less-efficiently than do ESCs). Retinal cells derived from hiPSCs have been generated by different laboratories worldwide, and some groups are currently setting up human clinical trials with hiPSC-derived RPE for treatment of age-related macular degeneration (e.g., pilot clinical study to assess the safety and feasibility of the transplantation of autologous iPSCs in patients with exudative agerelated macular degeneration started in Japan in 2013) (see http://www.riken.jp/en/pr/press/ 2013/20130730_1). Advances in research into iPSC applications for treatment of retinal degeneration were recently reviewed in detail by Cramer and MacLaren (2013).

\section{Sensory Substitution Devices}

Technologies transforming auditory or tactile information into visual sensory information have recently been developed. Clinical studies currently assess the capacities of the visualto-auditory sensory substitution device called "The vOICe." They showed that blind and blindfolded participants can locate and identify objects through images encoded by sound (Auvray et al. 2007; Merabet et al. 2009). Even congenitally fully blind adults could be taught to read and recognize complex images using "soundscapes," sounds topographically representing images (Striem-Amit et al. 2011, 2012a,b). Results of these studies clearly show the possibility of compensating for some effects of early and long-lasting or lifelong blindness or restore vision by providing visual-like experience via sensory substitution. BrainPort ${ }^{\circledR}$ is a device that translates information from a digital video camera to the tongue, because this organ has the capacity to act as a portal to convey somatosensory information to the visual cortex. The device uses a gentle electrical stimulation to create a tactile "image" that helps blind individuals to recognize high-contrast objects, their location and movement, and some aspects of perspective and depth (Sampaio et al. 2001; Chebat et al. 2007). As sensory substitution devices are noninvasive and cheap, although they require training in a scale of hours (Striem-Amit et al. 2012b), they represent an attractive alternative to other therapeutic approaches. They can serve as aids for the blind in daily visual tasks and can be used in combination with other therapeutic approaches for vision restoration.

\section{APPROPRIATE PATIENT EVALUATION AND SELECTION}

Identifying patients who can benefit from these innovative treatments is a crucial step in the process of assessing a patient's needs and selecting appropriate therapy. A key technology for this identification is in vivo, noninvasive imaging of the retina, which can provide objective clinical validation and may allow monitoring of both disease progression and treatment efficacy. Optical coherent tomography is particularly useful for examining retinal architecture and, more specifically, the outer retina structure, and photoreceptor inner/outer segment border. Adaptive optics fundus imaging is particularly suited for exploration of the healthy and dystrophic retinal structures, including photoreceptor detection and counting, and accurate documentation of RPE changes (Gocho et al. 2013). These high-resolution imaging techniques can help to select patients for clinical trials (e.g., to define the area of subretinal injection and diminish potential hazards resulting from injection) and may have important implications for establishing functional correlates and studying therapy outcomes. Functional studies (e.g., microperimetry) are also of crucial importance for establishing the benefit of these novel therapies, and they should be extended beyond testing visual field and visual acuity. Standardized mobility and task-related tests are needed both for assessment of the subjective visual handicap and for a reliable evaluation of the actual benefit for the patient. Development of new rehabilitation programs and devices, especially those that take advantage of visual plasticity (persisting even in old age) should be of paramount importance.

\section{CONCLUDING REMARKS}

An improved understanding of disease mechanisms is the first step in developing effective 
therapies for IRDs. To date, the advances in sequencing technologies have contributed to a rapid gain of knowledge and will certainly lead to discovery of new, as-yet unknown causative genes implicated in the pathophysiology of IRDs, with the ultimate goal of providing treatment for these incurable disorders. Indeed, a recent study using targeted RNA capture to perform large-scale validation of novel transcriptome features provided an unprecedented level of information regarding the human retinal transcriptome, identifying almost 30,000 novel exons and 116 putative novel genes (Farkas et al. 2013). Further studies will be required to uncover the function of these new genes in the retina. In addition to efficient and accurate genotyping, thorough clinical characterization of patients and families and genotype-phenotype association studies are the key toward improving diagnosis and allowing for appropriate genetic counseling with reliable predictions of disease course and prognosis. This knowledge will provide a foundation for development of preventive and/or therapeutic strategies, help to determine the risk/benefit profile of treatments and allow patients to make informed lifestyle decisions. The advent of several promising therapeutic approaches puts even more emphasis on genotype-phenotype correlations, extensive evaluation of disease markers during natural history, and analysis of treatment efficacy.

\section{REFERENCES}

Acland GM, Aguirre GD, Ray J, Zhang Q, Aleman TS, Cideciyan AV, Pearce-Kelling SE, Anand V, Zeng Y, Maguire AM, et al. 2001. Gene therapy restores vision in a canine model of childhood blindness. Nat Genet 28: 92-95.

Acland GM, Aguirre GD, Bennett J, Aleman TS, Cideciyan AV, Bennicelli J, Dejneka NS, Pearce-Kelling SE, Maguire AM, Palczewski K, et al. 2005. Long-term restoration of rod and cone vision by single dose rAAV-mediated gene transfer to the retina in a canine model of childhood blindness. Mol Ther 12: 1072-1082.

Adackapara CA, Sunness JS, Dibernardo CW, Melia BM, Dagnelie G. 2008. Prevalence of cystoid macular edema and stability in oct retinal thickness in eyes with retinitis pigmentosa during a 48-week lutein trial. Retina 28: 103-110.

Aleman TS, Duncan JL, Bieber ML, de Castro E, Marks DA, Gardner LM, Steinberg JD, Cideciyan AV, Maguire MG, Jacobson SG. 2001. Macular pigment and lutein supple- mentation in retinitis pigmentosa and Usher syndrome. Invest Ophthalmol Vis Sci 42: 1873-1881.

Ali RR, Sarra GM, Stephens C, Alwis MD, Bainbridge JW, Munro PM, Fauser S, Reichel MB, Kinnon C, Hunt DM, et al. 2000. Restoration of photoreceptor ultrastructure and function in retinal degeneration slow mice by gene therapy. Nat Genet 25: 306-310.

Allikmets R, Singh N, Sun H, Shroyer NF, Hutchinson A, Chidambaram A, Gerrard B, Baird L, Stauffer D, Peiffer A, et al. 1997. A photoreceptor cell-specific ATP-binding transporter gene $(A B C R)$ is mutated in recessive Stargardt macular dystrophy. Nat Genet 15: 236-246.

Amado D, Mingozzi F, Hui D, Bennicelli JL, Wei Z, Chen Y, Bote E, Grant RL, Golden JA, Narfstrom K, et al. 2010. Safety and efficacy of subretinal readministration of a viral vector in large animals to treat congenital blindness. Sci Transl Med 2: 21ra16.

Andreasson SO, Sandberg MA, Berson EL. 1988. Narrowband filtering for monitoring low-amplitude cone electroretinograms in retinitis pigmentosa. Am J Ophthalmol 105: 500-503.

Annear MJ, Bartoe JT, Barker SE, Smith AJ, Curran PG, Bainbridge JW, Ali RR, Petersen-Jones SM. 2011. Gene therapy in the second eye of RPE65-deficient dogs improves retinal function. Gene Ther 18: 53-61.

Audo I, Robson AG, Holder GE, Moore AT. 2008. The negative ERG: Clinical phenotypes and disease mechanisms of inner retinal dysfunction. Surv Ophthalmol 53: 16-40.

Auricchio A, Kobinger G, Anand V, Hildinger M, O'Connor E, Maguire AM, Wilson JM, Bennett J. 2001. Exchange of surface proteins impacts on viral vector cellular specificity and transduction characteristics: The retina as a model. Hum Mol Genet 10: 3075-3081.

Auvray M, Hanneton S, O'Regan JK. 2007. Learning to perceive with a visuo-auditory substitution system: Localisation and object recognition with 'the vOICe'. Perception 36: 416-430.

Ayuso C, Millan JM. 2010. Retinitis pigmentosa and allied conditions today: A paradigm of translational research. Genome Med 2: 34 .

Bahrami H, Melia M, Dagnelie G. 2006. Lutein supplementation in retinitis pigmentosa: PC-based vision assessment in a randomized double-masked placebo-controlled clinical trial [NCT00029289]. BMC Ophthalmol 6: 23.

Bainbridge JW, Smith AJ, Barker SS, Robbie S, Henderson R, Balaggan K, Viswanathan A, Holder GE, Stockman A, Tyler N, et al. 2008. Effect of gene therapy on visual function in Leber's congenital amaurosis. N Engl J Med 358: 2231-2239.

Barker SE, Broderick CA, Robbie SJ, Duran Y, Natkunarajah M, Buch P, Balaggan KS, MacLaren RE, Bainbridge JW, Smith AJ, et al. 2009. Subretinal delivery of adeno-associated virus serotype 2 results in minimal immune responses that allow repeat vector administration in immunocompetent mice. J Gene Med 11: 486-497.

Bayyoud T, Bartz-Schmidt KU, Yoeruek E. 2013. Long-term clinical results after cataract surgery with and without capsular tension ring in patients with retinitis pigmentosa: A retrospective study. BMJ Open 26: e002616.

Bemelmans AP, Bonnel S, Houhou L, Dufour N, Nandrot E, Helmlinger D, Sarkis C, Abitbol M, Mallet J. 2005. Retinal 
J.-A. Sahel et al.

cell type expression specificity of HIV-1-derived gene transfer vectors upon subretinal injection in the adult rat: Influence of pseudotyping and promoter. J Gene Med 7: 1367-1374.

Bennett J, Wilson J, Sun D, Forbes B, Maguire A. 1994. Adenovirus vector-mediated in vivo gene transfer into adult murine retina. Invest Ophthalmol Vis Sci 35: 2535-2542.

Bennett J, Tanabe T, Sun D, Zeng Y, Kjeldbye H, Gouras P, Maguire AM. 1996. Photoreceptor cell rescue in retinal degeneration $(r d)$ mice by in vivo gene therapy. Nat Med 2: $649-654$

Bennett J, Ashtari M, Wellman J, Marshall KA, Cyckowski LL, Chung DC, McCague S, Pierce EA, Chen Y, Bennicelli JL, et al. 2012. AAV2 gene therapy readministration in three adults with congenital blindness. Sci Transl Med 4: $120 \mathrm{ra} 115$.

Bereta G, Kiser PD, Golczak M, Sun W, Heon E, Saperstein DA, Palczewski K. 2008. Impact of retinal disease-associated RPE65 mutations on retinoid isomerization. Biochemistry 47: 9856-9865.

Berson EL, Rosner B, Sandberg MA, Hayes KC, Nicholson BW, Weigel-DiFranco C, Willett W. 1993. A randomized trial of vitamin A and vitamin E supplementation for retinitis pigmentosa. Arch Ophthalmol 111: 761-772.

Berson EL, Rosner B, Sandberg MA, Weigel-DiFranco C, Moser A, Brockhurst RJ, Hayes KC, Johnson CA, Anderson EJ, Gaudio AR, et al. 2004. Further evaluation of docosahexaenoic acid in patients with retinitis pigmentosa receiving vitamin A treatment: Subgroup analyses. Arch Ophthalmol 122: 1306-1314.

Berson EL, Rosner B, Sandberg MA, Weigel-DiFranco C, Brockhurst RJ, Hayes KC, Johnson EJ, Anderson EJ, Johnson CA, Gaudio AR, et al. 2010. Clinical trial of lutein in patients with retinitis pigmentosa receiving vitamin A. Arch Ophthalmol 128: 403-411.

Bessant DA, Ali RR, Bhattacharya SS. 2001. Molecular genetics and prospects for therapy of the inherited retinal dystrophies. Curr Opin Genet Dev 11: 307-316.

Bhalla S, Joshi D, Bhullar S, Kasuga D, Park Y, Kay CN. 2013. Long-term follow-up for efficacy and safety of treatment of retinitis pigmentosa with valproic acid. Br J Ophthalmol 97: 895-899.

Birch DG, Sandberg MA. 1996. Submicrovolt full-field cone electroretinograms: Artifacts and reproducibility. Doc Ophthalmol 92: 269-280.

Birch DG., Weleber RG, Duncan JL, Jaffe GJ., Tao W. 2013. Randomized trial of ciliary neurotrophic factor delivered by encapsulated cell intraocular implants for retinitis pigmentosa. Am J Ophthalmol 156: 283-292.

Blacharski P. 1988. Fundus flavimaculatus. In Retinal dystrophies and degenerations (ed. Newsome DA), pp. 135-159. Raven, New York.

Boughman JA, Vernon M, Shaver KA. 1983. Usher syndrome: Definition and estimate of prevalence from two high-risk populations. J Chronic Dis 36: 595-603.

Boyden ES, Zhang F, Bamberg E, Nagel G, Deisseroth K. 2005. Millisecond-timescale, genetically targeted optical control of neural activity. Nat Neurosci 8: 1263-1268.
Bunker CH, Berson EL, Bromley WC, Hayes RP, Roderick TH. 1984. Prevalence of retinitis pigmentosa in Maine. Am J Ophthalmol 97: 357-365.

Busskamp V, Duebel J, Balya D, Fradot M, Viney TJ, Siegert S, Groner AC, Cabuy E, Forster V, Seeliger M, et al. 2010. Genetic reactivation of cone photoreceptors restores visual responses in retinitis pigmentosa. Science 329: 413-417.

Busskamp V, Picaud S, Sahel JA, Roska B. 2011. Optogenetic therapy for retinitis pigmentosa. Gene Ther 19: 169-175.

Chebat DR, Rainville C, Kupers R, Ptito M. 2007. Tactile'visual' acuity of the tongue in early blind individuals. Neuroreport 18: 1901-1904.

Cideciyan AV, Aleman TS, Swider M, Schwartz SB, Steinberg JD, Brucker AJ, Maguire AM, Bennett J, Stone EM, Jacobson SG. 2004. Mutations in ABCA4 result in accumulation of lipofuscin before slowing of the retinoid cycle: A reappraisal of the human disease sequence. Hum Mol Genet 13: 525-534.

Cideciyan AV, Jacobson SG, Beltran WA, Sumaroka A, Swider M, Iwabe S, Roman AJ, Olivares MB, Schwartz SB, Komaromy AM, et al. 2013. Human retinal gene therapy for Leber congenital amaurosis shows advancing retinal degeneration despite enduring visual improvement. Proc Natl Acad Sci 110: E517-E525.

Clemson CM, Tzekov R, Krebs M, Checchi JM, Bigelow C, Kaushal S. 2011. Therapeutic potential of valproic acid for retinitis pigmentosa. Br J Ophthalmol 95: 89-93.

Colella P, Auricchio A. 2010. AAV-mediated gene supply for treatment of degenerative and neovascular retinal diseases. Curr Gene Ther 10: 371-380.

Conlon TJ, Deng WT, Erger K, Cossette T, Pang JJ, Ryals R, Clement N, Cleaver B, McDoom I, Boye SE, et al. 2013. Preclinical potency and safety studies of an AAV2-mediated gene therapy vector for the treatment of MERTK associated retinitis pigmentosa. Hum Gene Ther Clin Dev 24: 23-28.

Coppieters F, Lefever S, Leroy BP, De Baere E. 2010. CEP290, a gene with many faces: Mutation overview and presentation of CEP290base. Hum Mutat 31: 1097-1108.

Cramer AO, MacLaren RE. 2013. Translating induced pluripotent stem cells from bench to bedside: Application to retinal diseases. Curr Gene Ther 13: 139-151.

Cremers FP, van de Pol DJ, van Kerkhoff LP, Wieringa B, Ropers HH. 1990. Cloning of a gene that is rearranged in patients with choroideraemia. Nature 347: 674-677.

Cremers FP, van de Pol DJ, van Driel M, den Hollander AI, van Haren FJ, Knoers NV, Tijmes N, Bergen AA, Rohrschneider K, Blankenagel A, et al. 1998. Autosomal recessive retinitis pigmentosa and cone-rod dystrophy caused by splice site mutations in the Stargardt's disease gene ABCR. Hum Mol Genet 7: 355-362.

da Cruz L, Coley BF, Dorn J, Merlini F, Filley E, Christopher P, Chen FK, Wuyyuru V, Sahel J, Stanga P, et al. 2013. The Argus II epiretinal prosthesis system allows letter and word reading and long-term function in patients with profound vision loss. Br J Ophthalmol 97: 632-636.

Daiger SP, Bowne SJ, Sullivan LS. 2007. Perspective on genes and mutations causing retinitis pigmentosa. Arch Ophthalmol 125: 151-158. 
Dalkara D, Byrne LC, Klimczak RR, Visel M, Yin L, Merigan WH, Flannery JG, Schaffer DV. 2013. In vivo-directed evolution of a new adeno-associated virus for therapeutic outer retinal gene delivery from the vitreous. Sci Transl Med 5: p189ra176.

den Hollander AI, Roepman R, Koenekoop RK, Cremers FP. 2008. Leber congenital amaurosis: Genes, proteins and disease mechanisms. Prog Retin Eye Res 27: 391-419.

Dikopf MS, Chow CC, Mieler WF, Tu EY. 2013. Cataract extraction outcomes and the prevalence of zonular insufficiency in retinitis pigmentosa. Am J Ophthalmol 156: $82-88$.

Drivas TG, Holzbaur EL, Bennett J. 2013. Disruption of CEP290 microtubule/membrane-binding domains causes retinal degeneration. J Clin Invest 123: 4525-4539.

Dryja TP. 2000. Molecular genetics of Oguchi disease, fundus albipunctatus, and other forms of stationary night blindness: LVII Edward Jackson Memorial Lecture. Am J Ophthalmol 130: 547-563.

Dryja TP, McGee TL, Reichel E, Hahn LB, Cowley GS, Yandell DW, Sandberg MA, Berson EL. 1990. A point mutation of the rhodopsin gene in one form of retinitis pigmentosa. Nature 343: 364-366.

Dryja TP, Finn JT, Peng YW, McGee TL, Berson EL, Yau KW. 1995. Mutations in the gene encoding the $\alpha$ subunit of the rod cGMP-gated channel in autosomal recessive retinitis pigmentosa. Proc Natl Acad Sci 92: 10177-10181.

Falk MJ, Zhang Q, Nakamaru-Ogiso E, Kannabiran C, Fonseca-Kelly Z, Chakarova C, Audo I, Mackay DS, Zeitz C, Borman AD, et al. 2012. NMNAT1 mutations cause Leber congenital amaurosis. Nat Genet 44: 1040-1045.

Farkas MH, Grant GR, White JA, Sousa ME, Consugar MB, Pierce EA. 2013. Transcriptome analyses of the human retina identify unprecedented transcript diversity and $3.5 \mathrm{Mb}$ of novel transcribed sequence via significant alternative splicing and novel genes. BMC Genomics 14: 486.

Farrar GJ, Palfi A, O’Reilly M. 2010. Gene therapeutic approaches for dominant retinopathies. Curr Gene Ther 10: 381-388.

Fishman GA, Anderson RJ, Lourenco P. 1985. Prevalence of posterior subcapsular lens opacities in patients with retinitis pigmentosa. Br J Ophthalmol 69: 263-266.

Fishman GA, Gilbert LD, Fiscella RG, Kimura AE, Jampol LM. 1989. Acetazolamide for treatment of chronic macular edema in retinitis pigmentosa. Arch Ophthalmol 107: $1445-1452$.

Forsythe E, Beales PL. 2012. Bardet-Biedl syndrome. Eur J Hum Genet 21: 8-13.

Frasson M, Sahel JA, Fabre M, Simonutti M, Dreyfus H, Picaud S. 1999. Retinitis pigmentosa: Rod photoreceptor rescue by a calcium-channel blocker in the $r d$ mouse. Nat Med 5: 1183-1187.

Genead MA, Fishman GA, Rha J, Dubis AM, Bonci DM, Dubra A, Stone EM, Neitz M, Carroll J. 2011. Photoreceptor structure and function in patients with congenital achromatopsia. Invest Ophthalmol Vis Sci 52: 7298-7308.

George ND, Yates JR, Moore AT. 1995. X linked retinoschisis. Br J Ophthalmol 79: 697-702.
George ND, Yates JR, Moore AT. 1996. Clinical features in affected males with X-linked retinoschisis. Arch Ophthalmol 114: 274-280.

Gerber S, Rozet JM, Bonneau D, Souied E, Camuzat A, Dufier JL, Amalric P, Weissenbach J, Munnich A, Kaplan J. 1995. A gene for late-onset fundus flavimaculatus with macular dystrophy maps to chromosome 1p13. Am J Hum Genet 56: 396-399.

Gocho K, Sarda V, Falah S, Sahel JA, Sennlaub F, Benchaboune M, Ullern M, Paques M. 2013. Adaptive optics imaging of geographic atrophy. Invest Ophthalmol Vis Sci 54: 3673-3680.

Goldberg NR, Greenberg JP, Laud K, Tsang S, Freund KB. 2013. Outer retinal tubulation in degenerative retinal disorders. Retina 33: 1871-1876.

Gonzalez-Cordero A, West EL, Pearson RA, Duran Y, Carvalho LS, Chu CJ, Naeem A, Blackford SJ, Georgiadis A, Lakowski J, et al. 2013. Photoreceptor precursors derived from three-dimensional embryonic stem cell cultures integrate and mature within adult degenerate retina. Nat Biotechnol 31: 741-747.

Grover S, Fishman GA, Fiscella RG, Adelman AE. 1997. Efficacy of dorzolamide hydrochloride in the management of chronic cystoid macular edema in patients with retinitis pigmentosa. Retina 17: 222-231.

Hagiwara A, Yamamoto S, Ogata K, Sugawara T, Hiramatsu A, Shibata M, Mitamura Y. 2011. Macular abnormalities in patients with retinitis pigmentosa: Prevalence on OCT examination and outcomes of vitreoretinal surgery. Acta Ophthalmol 89: e122-e125.

Haim M. 2002. Epidemiology of retinitis pigmentosa in Denmark. Acta Ophthalmol Scand 80(S233): 1-34.

Hartong DT, Berson EL, Dryja TP. 2006. Retinitis pigmentosa. Lancet 368: 1795-1809.

Hauswirth WW, Aleman TS, Kaushal S, Cideciyan AV, Schwartz SB, Wang L, Conlon TJ, Boye SL, Flotte TR, Byrne BJ, et al. 2008. Treatment of Leber congenital amaurosis due to RPE65 mutations by ocular subretinal injection of adeno-associated virus gene vector: Short-term results of a phase I trial. Hum Gene Ther 19: 979-990.

Heckenlively J. 1982. The frequency of posterior subcapsular cataract in the hereditary retinal degenerations. Am J Ophthalmol 93: 733-738.

Heckenlively JR, Yoser SL, Friedman LH, Oversier JJ. 1988. Clinical findings and common symptoms in retinitis pigmentosa. Am J Ophthalmol 105: 504-511.

Hirami Y, Osakada F, Takahashi K, Okita K, Yamanaka S, Ikeda H, Yoshimura N, Takahashi M. 2009. Generation of retinal cells from mouse and human induced pluripotent stem cells. Neurosci Lett 458: 126-131.

Hoffman LM, Maguire AM, Bennett J. 1997. Cell-mediated immune response and stability of intraocular transgene expression after adenovirus-mediated delivery. Invest Ophthalmol Vis Sci 38: 2224-2233.

Hoffman DR, Locke KG, Wheaton DH, Fish GE, Spencer R, Birch DG. 2004. A randomized, placebo-controlled clinical trial of docosahexaenoic acid supplementation for $\mathrm{X}$-linked retinitis pigmentosa. Am J Ophthalmol 137: 704-718.

Hood DC, Holopigian K, Greenstein V, Seiple W, Li J, Sutter EE, Carr RE. 1998. Assessment of local retinal function in 
J.-A. Sahel et al.

patients with retinitis pigmentosa using the multi-focal ERG technique. Vision Res 38: 163-179.

Humayun MS, de Juan E Jr, Dagnelie G, Greenberg RJ, Propst RH, Phillips DH. 1996. Visual perception elicited by electrical stimulation of retina in blind humans. Arch Ophthalmol 114: 40-46.

Humayun MS, Weiland JD, Fujii GY, Greenberg R, Williamson R, Little J, Mech B, Cimmarusti V, Van Boemel G, Dagnelie G, et al. 2003. Visual perception in a blind subject with a chronic microelectronic retinal prosthesis. $\mathrm{Vi}$ sion Res 43: 2573-2581.

Humayun MS, Dorn JD, da Cruz L, Dagnelie G, Sahel JA, Stanga PE, Cideciyan AV, Duncan JL, Eliott D, Filley E, et al. 2012. Interim results from the international trial of Second Sight's visual prosthesis. Ophthalmology 119: 779-788.

Jackson H, Garway-Heath D, Rosen P, Bird AC, Tuft SJ. 2001. Outcome of cataract surgery in patients with retinitis pigmentosa. Br J Ophthalmol 85: 936-938.

Jacobson SG, Cideciyan AV, Ratnakaram R, Heon E, Schwartz SB, Roman AJ, Peden MC, Aleman TS, Boye SL, Sumaroka A, et al. 2012. Gene therapy for Leber congenital amaurosis caused by RPE65 mutations: Safety and efficacy in 15 children and adults followed up to 3 years. Arch Ophthalmol 130: 9-24.

Janssen A, Min SH, Molday LL, Tanimoto N, Seeliger MW, Hauswirth WW, Molday RS, Weber BH. 2008. Effect of late-stage therapy on disease progression in AAV-mediated rescue of photoreceptor cells in the retinoschisin-deficient mouse. Mol Ther 16: 1010-1017.

Jonas JB, Xu L, Wang YX. 2009. The Beijing Eye Study. Acto Ophthalmol 87: 247-261.

Kamenarova K, Cherninkova S, Romero Duran M, Prescott D, Valdes Sanchez ML, Mitev V, Kremensky I, Kaneva R, Bhattacharya SS, Tournev I, et al. 2013. A novel locus for autosomal dominant cone-rod dystrophy maps to chromosome 10q. Eur J Hum Genet 21: 338-342.

Kauper K, McGovern C, Sherman S, Heatherton P, Rapoza R, Stabila P, Dean B, Lee A, Borges S, Bouchard B, et al. 2012. Two-year intraocular delivery of ciliary neurotrophic factor by encapsulated cell technology implants in patients with chronic retinal degenerative diseases. Invest Ophthalmol Vis Sci 53: 7484-7491.

Kjellstrom S, Bush RA, Zeng Y, Takada Y, Sieving PA. 2007. Retinoschisin gene therapy and natural history in the $R s 1 h$-KO mouse: Long-term rescue from retinal degeneration. Invest Ophthalmol Vis Sci 48: 3837-3845.

Koenekoop RK. 2004. An overview of Leber congenital amaurosis: A model to understand human retinal development. Surv Ophthalmol 49: 379-398.

Koenekoop RK, Wang H, Majewski J, Wang X, Lopez I, Ren H, Chen Y, Li Y, Fishman GA, Genead M, et al. 2012. Mutations in NMNAT1 cause Leber congenital amaurosis and identify a new disease pathway for retinal degeneration. Nat Genet 44: 1035-1039.

Kohl S, Hamel C. 2013. Clinical utility gene card for: Achromatopsia-update 2013. EurJHum Genet 21. http:/ /www. nature.com/ejhg/journal/v21/n11/full/ejhg201344a.html

Kohl S, Coppieters F, Meire F, Schaich S, Roosing S, Brennenstuhl C, Bolz S, van Genderen MM, Riemslag FC, Lukowski R, et al. 2012. A nonsense mutation in
PDE6H causes autosomal-recessive incomplete achromatopsia. Am J Hum Genet 91: 527-532.

Koizumi H, Spaide RF, Fisher YL, Freund KB, Klancnik JM Jr, Yannuzzi LA. 2008. Three-dimensional evaluation of vitreomacular traction and epiretinal membrane using spectral-domain optical coherence tomography. Am J Ophthalmol 145: 509-517.

Komaromy AM, Alexander JJ, Rowlan JS, Garcia MM, Chiodo VA, Kaya A, Tanaka JC, Acland GM, Hauswirth WW, Aguirre GD. 2010. Gene therapy rescues cone function in congenital achromatopsia. Hum Mol Genet 19: 2581-2593.

Kong J, Kim SR, Binley K, Pata I, Doi K, Mannik J, ZernantRajang J, Kan O, Iqball S, Naylor S, et al. 2008. Correction of the disease phenotype in the mouse model of Stargardt disease by lentiviral gene therapy. Gene Ther 15: 13111320.

Lagali PS, Balya D, Awatramani GB, Munch TA, Kim DS, Busskamp V, Cepko CL, Roska B. 2008. Light-activated channels targeted to ON bipolar cells restore visual function in retinal degeneration. Nat Neurosci 11: 667-675.

Lamba DA, Gust J, Reh TA. 2009. Transplantation of human embryonic stem cell-derived photoreceptors restores some visual function in $\mathrm{Cr} x$-deficient mice. Cell Stem Cell 4: 73-79.

Lamba DA, McUsic A, Hirata RK, Wang PR, Russell D, Reh TA. 2010. Generation, purification and transplantation of photoreceptors derived from human induced pluripotent stem cells. PLoS ONE 5: e8763.

Lauritzen TZ, Harris J, Mohand-Said S, Sahel JA, Dorn JD, McClure K, Greenberg RJ. 2012. Reading visual braille with a retinal prosthesis. Front Neurosci 6: 168.

Leveillard T, Sahel JA. 2010. Rod-derived cone viability factor for treating blinding diseases: From clinic to redox signaling. Sci Transl Med 2: 26ps16.

Leveillard T, Mohand-Said S, Lorentz O, Hicks D, Fintz AC, Clerin E, Simonutti M, Forster V, Cavusoglu N, Chalmel F, et al. 2004. Identification and characterization of rodderived cone viability factor. Nat Genet 36: 755-759.

Li ZY, Kljavin IJ, Milam AH. 1995. Rod photoreceptor neurite sprouting in retinitis pigmentosa. $J$ Neurosci 15: 5429-5438.

Lin B, Masland RH, Strettoi E. 2009. Remodeling of cone photoreceptor cells after rod degeneration in $r d$ mice. Exp Eye Res 88: 589-599.

Liu X, Ondek B, Williams DS. 1998. Mutant myosin VIIa causes defective melanosome distribution in the RPE of shaker-1 mice. Nat Genet 19: 117-118.

Liu X, Udovichenko IP, Brown SD, Steel KP, Williams DS, 1999. Myosin VIIa participates in opsin transport through the photoreceptor cilium. J Neurosci 19: 62676274.

Lois N, Holder GE, Bunce C, Fitzke FW, Bird AC. 2001. Phenotypic subtypes of Stargardt macular dystrophyfundus flavimaculatus. Arch Ophthalmol 119: 359-369.

MacLaren RE, Pearson RA, MacNeil A, Douglas RH, Salt TE, Akimoto M, Swaroop A, Sowden JC, Ali RR. 2006. Retinal repair by transplantation of photoreceptor precursors. Nature 444: 203-207.

MacLaren RE, Groppe M, Barnard AR, Cottriall CL, Tolmachova T, Seymour L, Clark KR, During MJ, Cremers FP, 
Black GC, et al. 2014. Retinal gene therapy in patients with choroideremia: Initial findings from a phase 1/2 clinical trial. Lancet 383: 1129-1137.

Maeda T, Cideciyan AV, Maeda A, Golczak M, Aleman TS, Jacobson SG, Palczewski K. 2009. Loss of cone photoreceptors caused by chromophore depletion is partially prevented by the artificial chromophore pro-drug, 9cis-retinyl acetate. Hum Mol Genet 18: 2277-2287.

Maeda T, Dong Z, Jin H, Sawada O, Gao S, Utkhede D, Monk W, Palczewska G, Palczewski K. 2013. QLT091001, a 9-cis-retinal analog, is well-tolerated by retinas of mice with impaired visual cycles. Invest Ophthalmol Vis Sci 54: 455-466.

Maguire AM, Simonelli F, Pierce EA, Pugh EN Jr, Mingozzi F, Bennicelli J, Banfi S, Marshall KA, Testa F, Surace EM, et al. 2008. Safety and efficacy of gene transfer for Leber's congenital amaurosis. $N$ Engl J Med 358: 2240-2248.

Mathieson K, Loudin J, Goetz G, Huie P, Wang L, Kamins TI, Galambos L, Smith R, Harris JS, Sher A, et al. 2012. Photovoltaic retinal prosthesis with high pixel density. Nat Photonics 6: 391-397.

McLaughlin ME, Sandberg MA, Berson EL, Dryja TP. 1993. Recessive mutations in the gene encoding the $\beta$-subunit of rod phosphodiesterase in patients with retinitis pigmentosa. Nat Genet 4: 130-134.

Merabet LB, Battelli L, Obretenova S, Maguire S, Meijer P, Pascual-Leone A. 2009. Functional recruitment of visual cortex for sound encoded object identification in the blind. Neuroreport 20: 132-138.

Michaelides M, Hunt DM, Moore AT. 2004. The cone dysfunction syndromes. Br J Ophthalmol 88: 291-297.

Mitamura Y, Mitamura-Aizawa S, Nagasawa T, Katome T, Eguchi H, Naito T. 2012. Diagnostic imaging in patients with retinitis pigmentosa. J Med Invest 59: 1-11.

Miyake Y, Yagasaki K, Horiguchi M, Kawase Y, Kanda T. 1986. Congenital stationary night blindness with negative electroretinogram. A new classification. Arch Ophthalmol 104: $1013-1020$.

Murakami T, Akimoto M, Ooto S, Suzuki T, Ikeda H, Kawagoe N, Takahashi M, Yoshimura N. 2008. Association between abnormal autofluorescence and photoreceptor disorganization in retinitis pigmentosa. Am JOphthalmol 145: $687-694$.

Nagel G, Ollig D, Fuhrmann M, Kateriya S, Musti AM, Bamberg E, Hegemann P. 2002. Channelrhodopsin-1: A light-gated proton channel in green algae. Science 296: 2395-2398.

Nakazawa M, Ohguro H, Takeuchi K, Miyagawa Y, Ito T, Metoki T. 2011. Effect of nilvadipine on central visual field in retinitis pigmentosa: A 30-month clinical trial. Ophthalmologica 225: 120-126.

Naldini L, Blomer U, Gallay P, Ory D, Mulligan R, Gage FH, Verma IM, Trono D. 1996. In vivo gene delivery and stable transduction of nondividing cells by a lentiviral vector. Science 272: 263-267.

Nangia V, Jonas JB, Khare A, Sinha A. 2012. Prevalence of retinitis pigmentosa in India: The Central India Eye and Medical Study. Acta Ophthalmol 90: e649-e650.

Novarino G, Akizu N, Gleeson JG. 2011. Modeling human disease in humans: The ciliopathies. Cell 147: 70-79.
Osakada F, Ikeda $\mathrm{H}$, Mandai $\mathrm{M}$, Wataya T, Watanabe $\mathrm{K}$, Yoshimura N, Akaike A, Sasai Y, Takahashi M. 2008. Toward the generation of rod and cone photoreceptors from mouse, monkey and human embryonic stem cells. Nat Biotechnol 26: 215-224.

Park TK, Wu Z, Kjellstrom S, Zeng Y, Bush RA, Sieving PA, Colosi P. 2009. Intravitreal delivery of AAV8 retinoschisin results in cell type-specific gene expression and retinal rescue in the Rs1-KO mouse. Gene Ther 16: 916-926.

Petit C. 2001. Usher syndrome: From genetics to pathogenesis. Annu Rev Genomics Hum Genet 2: 271-297.

Pimenides D, George ND, Yates JR, Bradshaw K, Roberts SA, Moore AT, Trump D. 2005. X-linked retinoschisis: Clinical phenotype and RS1 genotype in 86 UK patients. $J$ Med Genet 42: e35.

Potter MJ, Wong E, Szabo SM, McTaggart KE. 2004. Clinical findings in a carrier of a new mutation in the choroideremia gene. Ophthalmology 111: 1905-1909.

Preising M, Ayuso C. 2004. Rab escort protein 1 (REP1) in intracellular traffic: A functional and pathophysiological overview. Ophthalmic Genet 25: 101-110.

Prokisch H, Hartig M, Hellinger R, Meitinger T, Rosenberg T. 2007. A population-based epidemiological and genetic study of X-linked retinitis pigmentosa. Invest Ophthalmol Vis Sci 48: 4012-4018.

Radtke ND, Aramant RB, Petry HM, Green PT, Pidwell DJ, Seiler MJ. 2008. Vision improvement in retinal degeneration patients by implantation of retina together with retinal pigment epithelium. Am J Ophthalmol 146: $172-182$.

Renner AB, Kellner U, Cropp E, Preising MN, MacDonald IM, van den Hurk JA, Cremers FP, Foerster MH. 2006. Choroideremia: Variability of clinical and electrophysiological characteristics and first report of a negative electroretinogram. Ophthalmology 113: 2066.e1-e10.

The Retinoschisis Consortium. 1998. Functional implications of the spectrum of mutations found in 234 cases with X-linked juvenile retinoschisis (XLRS). Hum Mol Genet 7: 1185-1192.

Robson AG, El-Amir A, Bailey C, Egan CA, Fitzke FW, Webster AR, Bird AC, Holder GE. 2003. Pattern ERG correlates of abnormal fundus autofluorescence in patients with retinitis pigmentosa and normal visual acuity. Invest Ophthalmol Vis Sci 44: 3544-3550.

Robson AG, Tufail A, Fitzke F, Bird AC, Moore AT, Holder GE, Webster AR. 2011. Serial imaging and structurefunction correlates of high-density rings of fundus autofluorescence in retinitis pigmentosa. Retina 31: 16701679.

Roepman R, van Duijnhoven G, Rosenberg T, Pinckers AJ, Bleeker-Wagemakers LM, Bergen AA, Post J, Beck A, Reinhardt R, Ropers HH, et al. 1996. Positional cloning of the gene for X-linked retinitis pigmentosa 3: Homology with the guanine-nucleotide-exchange factor RCC1. Hum Mol Genet 5: 1035-1041.

Romani M, Micalizzi A, Valente EM. 2013. Joubert syndrome: Congenital cerebellar ataxia with the molar tooth. Lancet Neurol 12: 894-905.

Ronquillo CC, Bernstein PS, Baehr W. 2012. Senior-Loken syndrome: A syndromic form of retinal dystrophy associated with nephronophthisis. Vision Res 75: 88-97. 
J.-A. Sahel et al.

Rosenfeld PJ, Cowley GS, McGee TL, Sandberg MA, Berson EL, Dryja TP. 1992. A null mutation in the rhodopsin gene causes rod photoreceptor dysfunction and autosomal recessive retinitis pigmentosa. Nat Genet 1: 209-213.

Sahel JA, Roska B. 2013. Gene therapy for blindness. Annu Rev Neurosci 36: 467-488.

Sampaio E, Maris S, Bach-y-Rita P. 2001. Brain plasticity: 'Visual' acuity of blind persons via the tongue. Brain Res 908: 204-207.

Sauer CG, Gehrig A, Warneke-Wittstock R, Marquardt A, Ewing CC, Gibson A, Lorenz B, Jurklies B, Weber BH. 1997. Positional cloning of the gene associated with $\mathrm{X}$ linked juvenile retinoschisis. Nat Genet 17: 164-170.

Schwartz SD, Hubschman JP, Heilwell G, Franco-Cardenas V, Pan CK, Ostrick RM, Mickunas E, Gay R, Klimanskaya I, Lanza R. 2012. Embryonic stem cell trials for macular degeneration: A preliminary report. Lancet 379: $713-$ 720.

Sen P, Bhargava A, George R, Ve Ramesh S, Hemamalini A Prema R, Kumaramanickavel G, Vijaya L. 2008. Prevalence of retinitis pigmentosa in South Indian population aged above 40 years. Ophthalmic Epidemiol 15: 279-281.

Sidjanin DJ, Lowe JK, McElwee JL, Milne BS, Phippen TM, Sargan DR, Aguirre GD, Acland GM, Ostrander EA. 2002. Canine CNGB3 mutations establish cone degeneration as orthologous to the human achromatopsia locus ACHM3. Hum Mol Genet 11: 1823-1833.

Sieving PA, Arnold EB, Jamison J, Liepa A, Coats C. 1998. Submicrovolt flicker electroretinogram: Cycle-by-cycle recording of multiple harmonics with statistical estimation of measurement uncertainty. Invest Ophthalmol Vis Sci 39: 1462-1469.

Sieving PA, Bingham EL, Kemp J, Richards J, Hiriyanna K. 1999. Juvenile X-linked retinoschisis from XLRS1 Arg213Trp mutation with preservation of the electroretinogram scotopic b-wave. Am J Ophthalmol 128: 179184.

Sieving PA, Caruso RC, Tao W, Coleman HR, Thompson DJ, Fullmer KR, Bush RA. 2006. Ciliary neurotrophic factor (CNTF) for human retinal degeneration: Phase I trial of CNTF delivered by encapsulated cell intraocular implants. Proc Natl Acad Sci 103: 3896-3901.

Stargardt K. 1909. Über familiäre, progressive degeneration under makulagegend des auges. Albrecht von Graefes Arch Ophthalmol 71: 534-550.

Stingl K, Bartz-Schmidt KU, Besch D, Braun A, Bruckmann A, Gekeler F, Greppmaier U, Hipp S, Hortdorfer G, Kernstock C, et al. 2013. Artificial vision with wirelessly powered subretinal electronic implant $\alpha$-IMS. Proc Biol Sci 280: 20130077

Striem-Amit E, Dakwar O, Reich L, Amedi A. 2011. The large-scale organization of "visual" streams emerges without visual experience. Cereb Cortex 22: 1698-1709.

Striem-Amit E, Cohen L, Dehaene S, Amedi A. 2012a. Reading with sounds: Sensory substitution selectively activates the visual word form area in the blind. Neuron 76: 640652.

Striem-Amit E, Guendelman M, Amedi A. 2012b. 'Visual' acuity of the congenitally blind using visual-to-auditory sensory substitution. PLoS ONE 7: e33136.
Sun H, Nathans J. 1997. Stargardt's ABCR is localized to the disc membrane of retinal rod outer segments. Nat Genet 17: $15-16$.

Takano Y, Ohguro H, Dezawa M, Ishikawa H, Yamazaki H, Ohguro I, Mamiya K, Metoki T, Ishikawa F, Nakazawa M. 2004. Study of drug effects of calcium channel blockers on retinal degeneration of $r d$ mouse. Biochem Biophys Res Commun 313: 1015-1022.

Talcott KE, Ratnam K, Sundquist SM, Lucero AS, Lujan BJ, Tao W, Porco TC, Roorda A, Duncan JL. 2011. Longitudinal study of cone photoreceptors during retinal degeneration and in response to ciliary neurotrophic factor treatment. Invest Ophthalmol Vis Sci 52: 2219-2226.

Testa F, Maguire AM, Rossi S, Pierce EA, Melillo P, Marshall K, Banfi S, Surace EM, Sun J, Acerra C, et al. 2013. Threeyear follow-up after unilateral subretinal delivery of adeno-associated virus in patients with Leber congenital amaurosis type 2. Ophthalmology 120: 1283-1291.

Thompson DA, Li Y, McHenry CL, Carlson TJ, Ding X, Sieving PA, Apfelstedt-Sylla E, Gal A. 2001. Mutations in the gene encoding lecithin retinol acyltransferase are associated with early-onset severe retinal dystrophy. Nat Genet 28: 123-124.

Tojo N, Nakamura T, Fuchizawa C, Oiwake T, Hayashi A. 2013. Adaptive optics fundus images of cone photoreceptors in the macula of patients with retinitis pigmentosa. Clin Ophthalmol 7: 203-210.

Tolmachova T, Tolmachov OE, Wavre-Shapton ST, TraceyWhite D, Futter CE, Seabra MC. 2012. CHM/REP1 cDNA delivery by lentiviral vectors provides functional expression of the transgene in the retinal pigment epithelium of choroideremia mice. J Gene Med 14: 158-168.

Tschernutter M, Schlichtenbrede FC, Howe S, Balaggan KS, Munro PM, Bainbridge JW, Thrasher AJ, Smith AJ, Al RR. 2005. Long-term preservation of retinal function in the RCS rat model of retinitis pigmentosa following lentivirus-mediated gene therapy. Gene Ther 12: 694-701.

Tsujikawa M, Wada Y, Sukegawa M, Sawa M, Gomi F, Nishida K, Tano Y. 2008. Age at onset curves of retinitis pigmentosa. Arch Ophthalmol 126: 337-340.

Tsybovsky Y, Molday RS, Palczewski K. 2010. The ATP-binding cassette transporter ABCA4: Structural and functional properties and role in retinal disease. Adv Exp Med Biol 703: $105-125$.

Van Hooser JP, Aleman TS, He YG, Cideciyan AV, Kuksa V, Pittler SJ, Stone EM, Jacobson SG, Palczewski K. 2000. Rapid restoration of visual pigment and function with oral retinoid in a mouse model of childhood blindness. Proc Natl Acad Sci 97: 8623-8628.

van Reeuwijk J, Arts HH, Roepman R. 2011. Scrutinizing ciliopathies by unraveling ciliary interaction networks. Hum Mol Genet 20: R149-R157.

Vandenberghe LH, Auricchio A. 2012. Novel adeno-associated viral vectors for retinal gene therapy. Gene Ther 19: $162-168$.

Vasireddy V, Mills JA, Gaddameedi R, Basner-Tschakarjan E, Kohnke M, Black AD, Alexandrov K, Zhou S, Maguire AM, Chung DC, et al. 2013. AAV-mediated gene therapy for Choroideremia: Preclinical studies in personalized models. PLoS ONE 8: e61396.

Waters AM, Beales PL. 2011. Ciliopathies: An expanding disease spectrum. Pediatr Nephrol 26: 1039-1056. 
Witkin AJ, Ko TH, Fujimoto JG, Chan A, Drexler W, Schuman JS, Reichel E, Duker JS. 2006. Ultra-high resolution optical coherence tomography assessment of photoreceptors in retinitis pigmentosa and related diseases. Am J Ophthalmol 142: 945-952.

Yang Y, Mohand-Said S, Danan A, Simonutti M, Fontaine V, Clerin E, Picaud S, Leveillard T, Sahel JA. 2009. Functional cone rescue by RdCVF protein in a dominant model of retinitis pigmentosa. Mol Ther 17: 787-795.

Yatsenko AN, Shroyer NF, Lewis RA, Lupski JR. 2001. Lateonset Stargardt disease is associated with missense mutations that map outside known functional regions of ABCR (ABCA4). Hum Genet 108: 346-355.

You QS, Xu L, Wang YX, Liang QF, Cui TT, Yang XH, Wang S, Yang H, Jonas JB. 2013. Prevalence of retinitis pigmentosa in North China: The Beijing Eye Public Health Care Project. Acta Ophthalmol 91: e499-e500.

Zeitz C, Jacobson SG, Hamel CP, Bujakowska K, Neuille M, Orhan E, Zanlonghi X, Lancelot ME, Michiels C, Schwartz SB, et al. 2013. Whole-exome sequencing identifies LRIT3 mutations as a cause of autosomal-recessive complete congenital stationary night blindness. Am J Hum Genet 92: 67-75.
Zeng Y, Takada Y, Kjellstrom S, Hiriyanna K, Tanikawa A, Wawrousek E, Smaoui N, Caruso R, Bush RA, Sieving PA. 2004. RS-1 gene delivery to an adult Rsih knockout mouse model restores ERG b-wave with reversal of the electronegative waveform of X-linked retinoschisis. Invest Ophthalmol Vis Sci 45: 3279-3285.

Zhang K, Kniazeva M, Han M, Li W, Yu Z, Yang Z, LiY, Metzker ML, Allikmets R, Zack DJ, et al. 2001. A 5-bp deletion in ELOVL4 is associated with two related forms of autosomal dominant macular dystrophy. Nat Genet 27: 89-93.

Zhang F, Wang LP, Brauner M, Liewald JF, Kay K, Watzke N, Wood PG, Bamberg E, Nagel G, Gottschalk A, et al. 2007. Multimodal fast optical interrogation of neural circuitry. Nature 446: 633-639.

Zhao X, Liu J, Ahmad I. 2002. Differentiation of embryonic stem cells into retinal neurons. Biochem Biophys Res Commun 297: 177-184.

Zrenner E. 2002. Will retinal implants restore vision? Science 295: $1022-1025$.

Zrenner E, Bartz-Schmidt KU, Benav H, Besch D, Bruckmann A, Gabel VP, Gekeler F, Greppmaier U, Harscher A, Kibbel S, et al. 2011. Subretinal electronic chips allow blind patients to read letters and combine them to words. Proc Biol Sci 278: 1489-1497. 


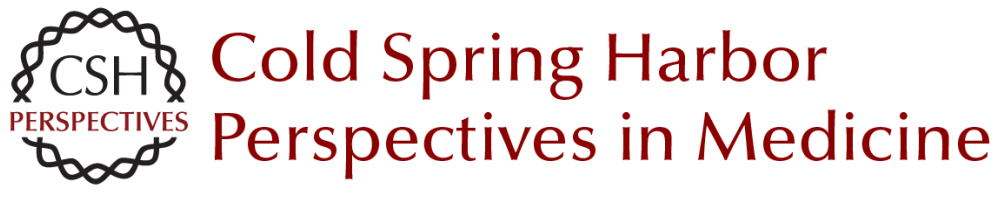

\title{
Clinical Characteristics and Current Therapies for Inherited Retinal Degenerations
}

\author{
José-Alain Sahel, Katia Marazova and Isabelle Audo
}

Cold Spring Harb Perspect Med 2015; doi: 10.1101/cshperspect.a017111 originally published online October 16, 2014

Subject Collection Retinal Disorders: Genetic Approaches to Diagnosis and Treatment

Trial by "Firsts": Clinical Trial Design and Regulatory Considerations in the Development and Approval of the First AAV Gene Therapy

Product in the United States

Kathleen Z. Reape and Katherine A. High

Immunology of Retinitis Pigmentosa and Gene Therapy-Associated Uveitis

Paul Yang, Debarshi Mustafi and Kathryn L. Pepple

Developing New Vectors for Retinal Gene Therapy Emilia A. Zin, Bilge E. Ozturk, Deniz Dalkara, et al.

Beyond the NEI-VFQ: Recent Experience in the Development and Utilization of Patient-Reported Outcomes for Inherited Retinal Diseases

Todd Durham, Judit Banhazi, Francesco Patalano, et al.

Electronic Retinal Prostheses Daniel Palanker

Alternative RNA Splicing in the Retina: Insights and Perspectives

Casey J. Keuthan, Sadik Karma and Donald J. Zack

X-Linked Retinoschisis

Cristy A. Ku, Lisa W. Wei and Paul A. Sieving

A Systematic Review of Optogenetic Vision Restoration: History, Challenges, and New Inventions from Bench to Bedside

Antonia Stefanov and John G. Flannery
Lessons Learned from the Development of the

First FDA-Approved Gene Therapy Drug, Voretigene Neparvovec-rzyl Jean Bennett and Albert M. Maguire

Therapeutic Gene Editing in Inherited Retinal Disorders Jinjie Ling, Laura A. Jenny, Ashley Zhou, et al.

Cell-Based Therapies: Strategies for Regeneration Marina Pavlou and Thomas A. Reh

The Importance of Natural History Studies in Inherited Retinal Diseases Allison Ayala, Janet Cheetham, Todd Durham, et al.

\section{Photoreceptor Cell Replacement Using \\ Pluripotent Stem Cells: Current Knowledge and \\ Remaining Questions}

Christelle Monville, Olivier Goureau and Karim Ben M'Barek

iPSC-RPE in Retinal Degeneration: Recent

Advancements and Future Perspectives

Tadao Maeda and Masayo Takahashi

Retinal Degeneration Animal Models in Bardet-

Biedl Syndrome and Related Ciliopathies

Clarisse Delvallée and Hélène Dollfus

Mobility Testing and Other Performance-Based Assessments of Functional Vision in Patients with Inherited Retinal Disease

Daniel Chung, Colas Authié and Laure Blouin

For additional articles in this collection, see http://perspectivesinmedicine.cshlp.org/cgi/collection/ 
For additional articles in this collection, see http://perspectivesinmedicine.cshlp.org/cgi/collection/ 